\title{
The Spectrum of Wind Speed Fluctuations Encountered by a Rotating Blade of a Wind Energy Conversion System: Observations and Theory
}

J. R. Connell

November 1981

Prepared for the U.S. Department of Energy under Contract DE-AC06-76RLO 1830

Pacific Northwest Laboratory Operated for the U.S. Department of Energy by Battelle Memorial Institute 
NOTICE

This report was prepared as an account of work sponsored by the United States Government. Neither the United States nor the Department of Energy, nor any of their employees, nor any of their contractors, subcontractors, or their employees. makes any warranty, express or implied, or assumes any legal liability or responsibility for the accuracy. completeness or usefulness of any information, apparatus. product or process disclosed, or represents that its use would not infringe privately owned rights.

The views, opinions and conclusions contained in this report are those of the contractor and do not necessarily represent those of the United States Government or the United States Department of Energy.

\author{
PACIFIC NORTHWEST LABORATORY \\ operated by \\ BATTELLE \\ for the \\ UNITED STATES DEPARTMENT OF ENERGY \\ Under Contract DE-AC06-76RLO 1830
}

\author{
Printed in the United States of America \\ Available from \\ National Technical Information Service \\ United States Department of Commerce \\ 5285 Port Royal Road \\ Springfield. Virginia 22151
}

Price: Printed Copy \$

$\therefore$ Microfiche $\$ 3.00$

$\begin{array}{cc}\text { Pages } & \text { Selling Price } \\ 001-025 & \$ 4.00 \\ 026-050 & \$ 4.50 \\ 051-075 & \$ 5.25 \\ 076-100 & \$ 6.00 \\ 101-125 & \$ 6.50 \\ 126-150 & \$ 7.25 \\ 151-175 & \$ 8.00 \\ 176-200 & \$ 9.00 \\ 201-225 & \$ 9.25 \\ 226-250 & \$ 9.50 \\ 251-275 & \$ 10.75 \\ 276-300 & \$ 11.00\end{array}$


THE SPECTRUM OF WIND SPEED

FLUCTUATIONS ENCOUNTERED BY A ROTATING BLADE OF A WIND ENERGY CONVERSION SYSTEM:

OBSERVATIONS AND THEORY

J. R. Connell

November 1981

Prepared for

the U.S. Department of Energy

under Contract DE-AC06-76RLO 1830

Pacific Northwest Laboratory

Richland, Washington 99352 
$\cdot$
+
$\cdot$
$\cdot$

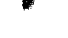

. 


\section{PREFACE}

Wind turbines are nearly unique among machines in that they must be dynamic, light, and yet strong enough to withstand substantial and continuing turbulent wind force in the atmospheric boundary layer. A program to optimize the cost of energy generated under such stringent conditions requires attention to the effects of wind in considerable detail during the design, testing and operation of the wind turbine.

This report is one of a series done within the Design and Performance Evaluation Group of the Wind Characteristics Program Element of the Federal Wind Energy Program. The group is responsible for characterizing atmospheric properties in ways that are useful for designing and analyzing wind turbine response. This research includes the following components:

1. Restructuring and interpreting published conventional meteorological data for application to Wind Energy Conversion Systems (WECS).

2. Developing new characterizations of wind properties.

3. Describing wind characteristics at each important, distinctly different class of wind turbine site.

The ultimate objective of technical reports from work done in the Wind Characteristics Program Element is to provide practical information in a form easily interpreted and used by the engineering designer of WECS. The reports may have several different orientations. For example, some reports contain meteorological, mathematical and/or measurement detail or elaboration that provide advanced understanding of wind characteristics. These reports will subsequently be condensed and combined with other related reports to provide a more practical and general reference. Other reports represent multidisciplinary efforts, e.g., of engineers, atmospheric scientists, physicists, and mathematicians. Still other reports provide advanced understanding of wind characteristics and revelation of unsuspected features of machine-wind interactions that should be considered by the wind energy community in design of machines. By quickly making this information known to users, we anticipate that research and improvement of the information will occur, and that some potential problems 
of machine-wind interactions will be brought to the attention of designers. We expect that in some cases there will be a need for later reports to condense this information and incorporate related work into more practical reference documents.

In brief, a diversity of topics and their treatment ranging from practical engineering design curves to rather fuller scientific expositions of the subject matter are to be found in our publications. All reports are directed toward the ultimate, but not distant, goal of having accurate and representative characteristics of the wind-turbine layer of the atmosphere for use in the design and evaluation of performance of WECS.

This report proves that the characteristics of turbulence that are experienced by a rotating wind turbine rotor blade are in principle and in practice very different than those experienced by a nonrotating rotor blade. Thus conventional wind characteristics, which are formulated for the nonrotating frame of reference, are more inaccurate than generally supposed. The measurements and mathematical model that are presented for turbulence observed in the rotating frame of reference represent the third phase of the Pacific Northwest Laboratory work aimed at providing an accurate turbulence description for use in the design and evaluation of the performance of wind turbines. The first phase of work was the measurement of wind with a vertical plane array of anemometers. The second phase was the physical interpretation of the measurements in terms of implications for wind turbine rotors and initiation of development of a model of wind/wind turbine interaction. The third phase involved measurement of turbulence by rotating sensors and mathematical development of a physical model of this representation of turbulence as independent checks and expansions of the vertical plane array results. A fourth phase, to correlate real wind turbine response with rotationally measured turbulence and thereby understand the wind/wind turbine interaction, is in progress and preliminary results are quite promising. They will be reported soon.

An earlier version of the present report was accepted in 1980, with recommended revisions, for publication in the Journal of Solar Energy. The revised version, reported herein, is to be published by that journal under the 
slightly shorter title "The Spectrum of Wind Speed Fluctuations Encountered by a Rotating Blade of a Wind Energy Conversion System."

This PNL report includes one appendix which is not included in the journal article. The appendix describes rotationally observed turbulence in terms of gust amplitude and duration probabilities as opposed to the spectral description used in the main text of the report. 


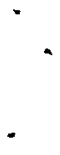

$+$ 
A point on a rotating wind turbine blade encounters turbulence whose characteristics are quite different from turbulence measured by a stationary anemometer. This is true for vertical as well as horizontal axis wind turbines. The spectrum of the observed turbulence is distorted in several subranges of frequency in characteristic ways. The midfrequency region is depleted and the removed energy is distributed into the high frequency end of the spectrum. The resulting two-peaked continuous spectrum also contains narrow-band spikes of turbulence energy centered on the frequency of rotor rotation and multiples of that frequency. The probability statistics of gusts also are distinct for the rotational cases.

The rotational sampling effect on wind spectra is quantified using measurements of wind velocity at circular arrays of anemometers and measurements by laser and hotwire anemometers traversing crosswind circular paths. All results show a reduction of energy in turbulence fluctuations by a factor of 5 to 10 in the frequency range around $0.1 \mathrm{~Hz}$. They show a similar magnitude of increase in the frequency range greater than the circular rotation rate (the $1 \mathrm{P}$ frequency in turbine nomenclature). In addition large amounts of energy are found at the $1 \mathrm{P}$ frequency and multiples of $1 \mathrm{P}$ up to at least $4 \mathrm{P}$.

A simple theoretical model of the spectrum of turbulence, which is rotationally sampled, is developed. The model, which assumes homogeneous, isotropic turbulence, reproduces the shape of the spectrum observed. This includes general decrease of energy around $0.1 \mathrm{~Hz}$ and general increase above $1 \mathrm{P}$ as well as the narrow bands of energy at multiples of $P$. Two nondimensional parameters are derived for use in scaling the model for various turbine and atmospheric conditions. One parameter is the ratio of length of rotor blade to the integral length scale of the turbulence. The other parameter is the ratio of the frequency of fluctuation of characteristic large eddies in the atmospheric boundary layer at turbine height to the frequency of rotation of the turbine. Several model variations for different values of the parameters produce spectra which are quite different from each other in the general energy distribution as well as in the bands of energy which occur. 
The results are shown to provide a basis for improving turbine design, siting and control. This includes criteria for selecting rotor height, diameter and rotation rate. They provide guidelines for optimizing a design once the preliminary turbine configuration has been chosen. Additional reasons are provided for the generally intuitive understanding that raising turbines to greater heights can improve the chances of survival of turbines.

The theory can be readily modified to account for some more realistic winds. Although mean wind shear is an important stress factor, fluctuating wind shears in all directions account for a large portion of the high frequency bands of turbulence energy. Therefore, the effect should be experienced by vertical axis turbines also. The model can be modified to correspond to this case. 


\section{CONTENTS}

PREFACE

SUMMARY

1. INTRODUCTION

2. WIND SPECTRA MEASURED WITH VERTICAL PLANE ARRAYS

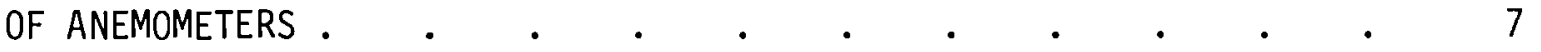

3. WIND SPECTRA MEASURED WITH LASER AND HOTWIRE ANEMOMETERS SWEEPING THROUGH CIRCULAR CROSSWIND PATHS $\quad \cdot \quad \cdot \quad \cdot \quad \cdot \quad \cdot 11$

4. A THEORETICAL MODEL OF THE SPECTRUM OF AXIAL TURBULENCE OBSERVED AT A POINT REVOLVING AROUND A CROSSWIND CIRCULAR PATH • • • • 15

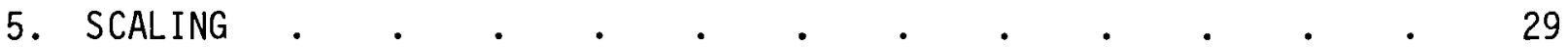

6. COMPARISON OF THEORETICAL SPECTRA WITH MEASURED SPECTRA $\quad$ • • 31

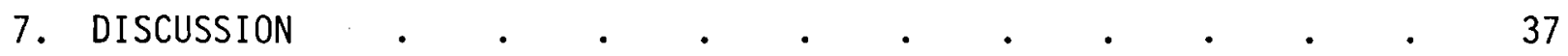

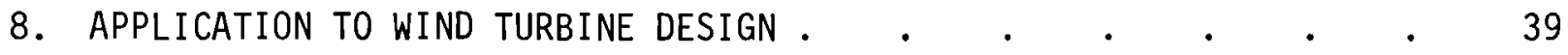

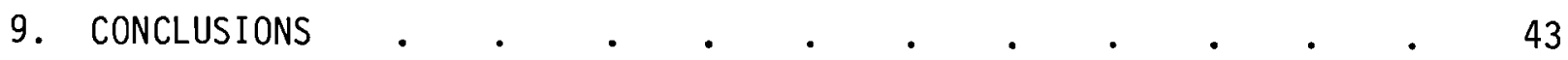

REFERENCES $\quad$ •

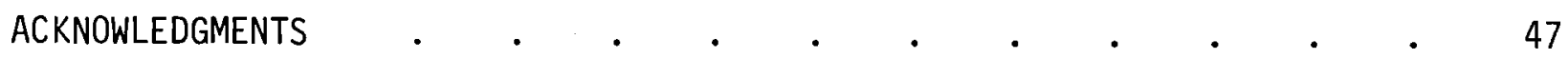

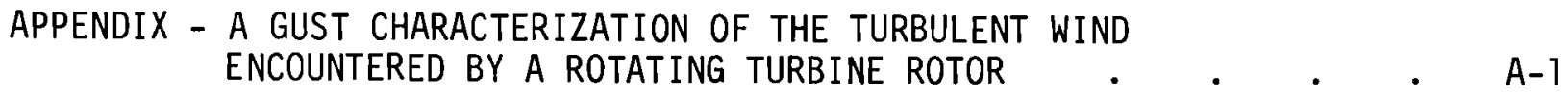




\section{FIGURES}

1 Illustration of the Difference in Character of Turbulent Wind as Observed by a Fixed Anemometer and a Point on a Rotating Blade of a Wind Turbine.

2 Scale Drawing of the $49 \mathrm{~m}$ Diameter Vertical Plane Array of Anemometers Used at the Pacific Northwest Laboratory a Rotating Blade of a Wind Turbine.

4 Spectra of Wind Fluctuations Derived From Measurements of Wind by Rotationally Sampling Wind Speed Values Around a Circular Array of Anemometers in a Vertical Plane

5 Spectra of Axial Wind Speed, U, From Wind Measurements Made by a Laser Anemometer Scanning a Circle in a Vertical Plane.

6 Axial Wind Speed Spectrum From Wind Measurements Made by a Hotwire Anemometer Traversing a Circle in a Vertical Plane

7 A Drawing of the Geometry of the Separation Distance, s, for Two Points on the Vertical Circle as a Function of Time, $\tau$.

8 Graph Showing the Expected Form of the Two Point-Time Lag Correlation of Axial Wind Speed Between Points 1 and 2 Based Upon Simple Physical Reasoning Given in the Text .

9 A Comparison of Two Double Spatial Correlation Functions of the Wind Speed in the Mean Wind Direction . . . . . . 24

10 Plots of the Wind Speed Spectra for Rotationally Observed Wind Derived From the Formulas of a) Rosenbrock and

b) Connel1

11 A Family of Spectra for the Axial Wind Sampled Rotationally in a Circle in the Crosswind Plane, Derived From the New Formulation by Connell

12 Plots of the Wind Speed Spectra for Rotationally Observed Wind Adapted From a) Holley and b) Fichtl

13 Universal Features of the Spectrum of Rotationally Sampled Wind and the Corresponding Nomenclature.

14 Comparison of the New Model of the Spectrum of Rotationally Sampled Turbulence Against Observed Spectra 


\section{FIGURES (Continued)}

A.1 Modification of the Observed Character of Fluctuating Wind Encountered at the Same Time by Two Differently Moving Systems

A.2 Speed and Duration Curves of Three Sizes of Gust Observed From Three Different Frames of Reference . . . . . A.4

A.3 Probability Density Distribution of Amplitudes Observed in the Rotating Frame of Reference for Gusts That are Characterized as Gust Zero Events . . . . . . . . A.6

\section{$\underline{\text { TABLES }}$}

1 Scale Dependence of Rotational Sampling Modifications of Turbulence Spectra .

2 Comparison of Theory and Observations of Wind Spectra . . . 33 


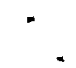

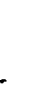

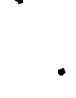




\section{INTRODUCTION}

Wind fluctuations may strongly affect wind turbine fatigue, power output quality and control system programming. For turbine design purposes, it is important to know in what amounts turbulence energy is distributed among the potentially significant periods or frequencies of fluctuation. A typical method of determining turbine design considers the characteristics of turbulence observed at nonmoving positions. In principle, and probably in practice, this is inaccurate.

Unlike the anemometer fixed on a tower, a point on a wind turbine rotor moves across the atmospheric boundary layer wind field in a large circular path. Thus turbulence characteristics of the wind that are observed by the turning rotor are different from those of the nonturning rotor. Figure 1 illustrates the most obvious aspect of the difference. Here the wind fluctuations having intermediate and short periods, with respect to the Eulerian spectrum of the longitudinal wind speed, are compressed in time, as seen in the rotating frame of reference of a point on the turbine blade.

The wind fluctuation properties may be characterized in several ways for use in design criteria. One method, Fourier spectrum analysis, has long been used in modern wind engineering and aircraft design. The Fourier spectrum description of turbulence has also been a preferred method of statistically summarizing amplitude and time scale information about the atmosphere. Since much wind turbine design uses a gust or rise rate description of the wind, this form of analysis should also be done for the rotating frame of reference. However, the present paper uses spectral analys is to characterize wind fluctuations observed at a blade of a turning wind turbine rotor.

An observational method of obtaining the properties of turbulence that a rotating blade experiences is, in principle, not complicated. Several arrays of anemometers placed in fixed locations in a vertical plane have been used at Pacific Northwest Laboratory (PNL). The earliest study of this type was done by Verholek [1], who placed the anemometers at uniform intervals on a circle in the vertical plane (see Figure 2). The wind velocity sensed by each anemometer is continuously sampled and recorded. The wind characteristics at the 

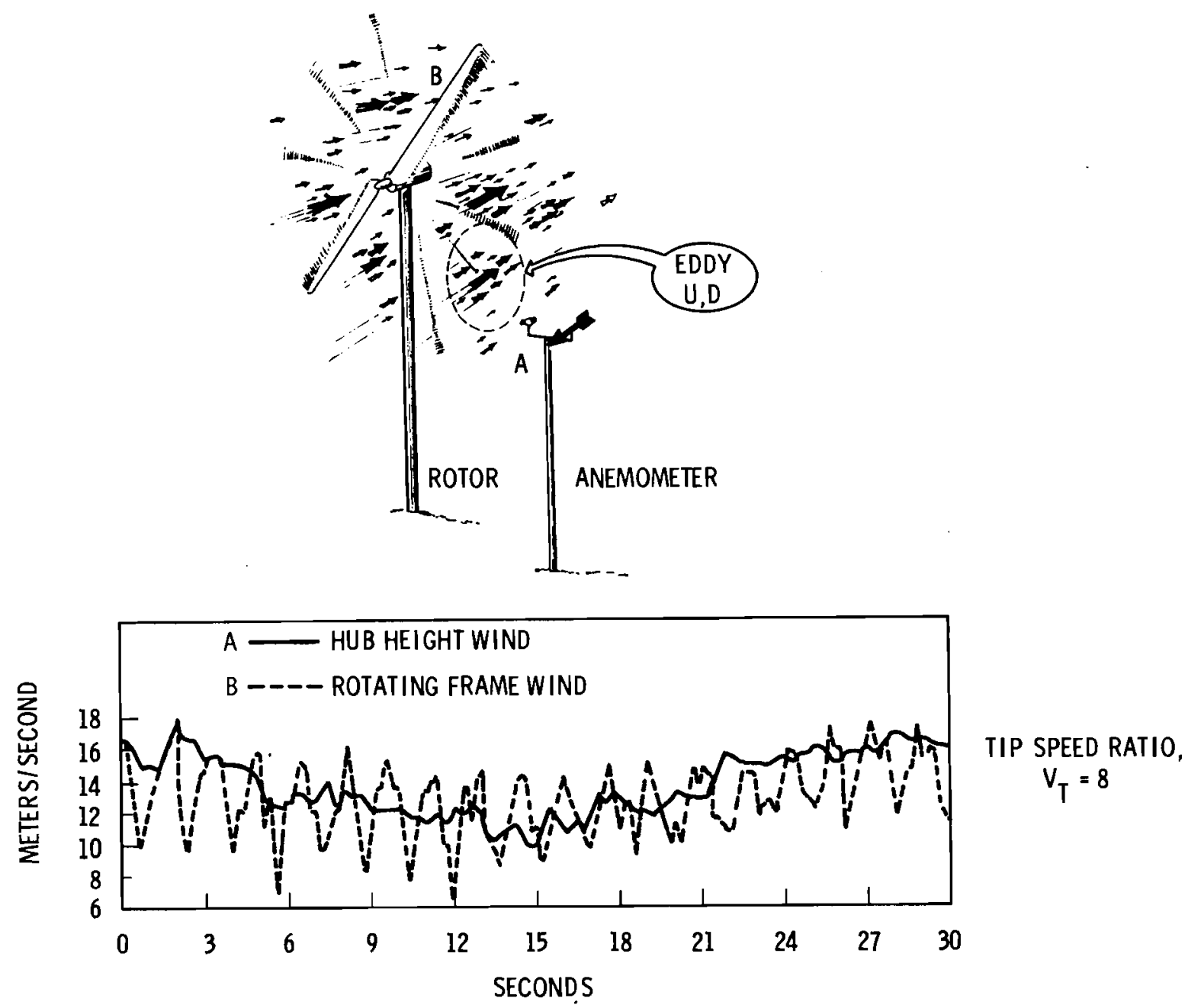

FIGURE 1. Illustration of the Difference in Character of Turbulent Wind as Observed by a Fixed Anemometer and a Point on a Rotating Blade of a Wind Turbine. The two curves at the bottom of the figure are from real measurements of the wind using a vertical plane array of anemometers. The dashed line corresponds to the wind encountered at point $B$ on the turbine rotor, for a rotation rate of 1 revolution $/ 1.6 \mathrm{~s}$ and a radius of $25 \mathrm{~m}$. The solid line corresponds to wind measured at the anemometer (point A). 


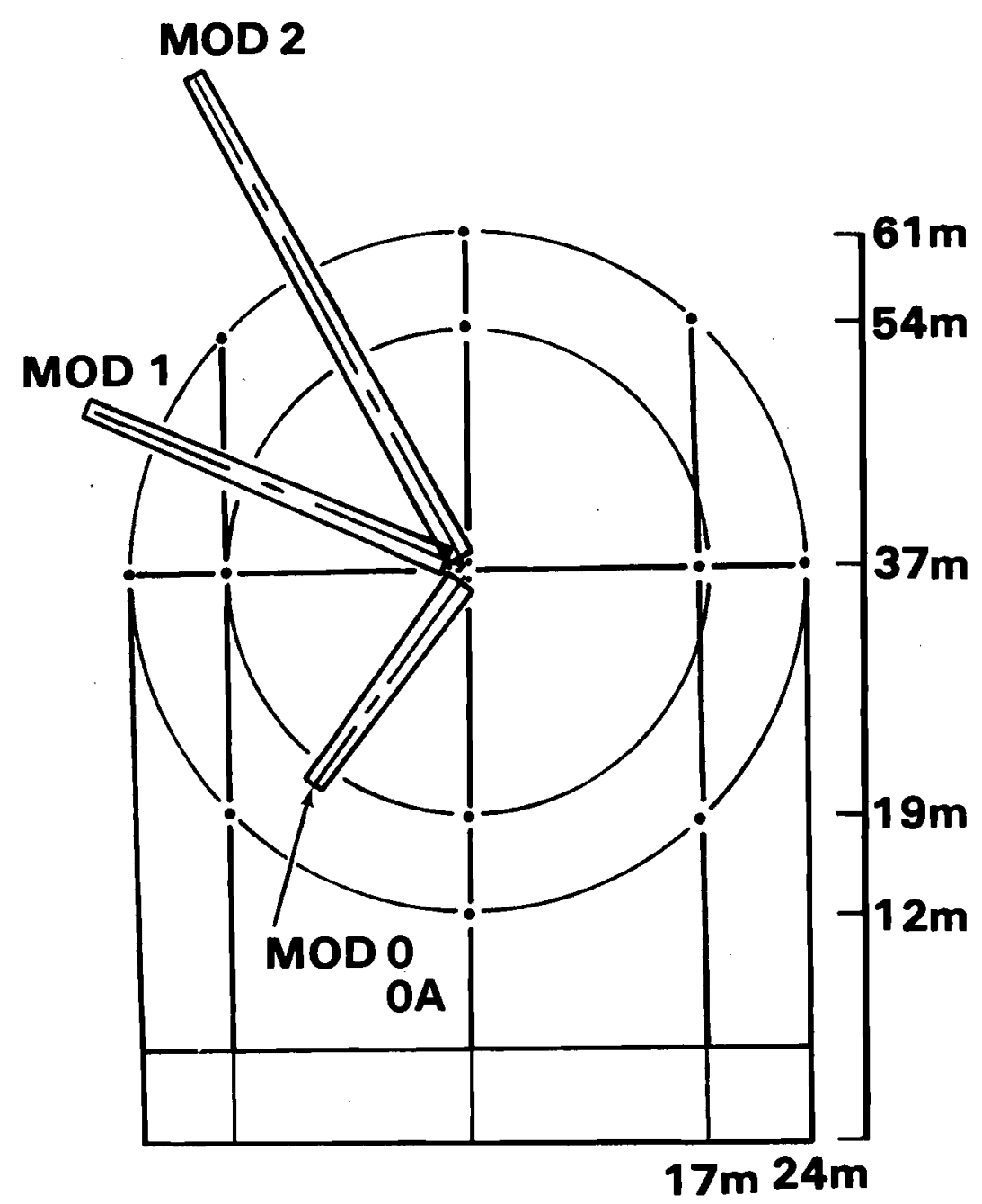

FIGURE 2. Scale Drawing of the $49 \mathrm{~m}$ Diameter Vertical Plane Array of Anemometers Used at the Pacific Northwest Laboratory. The anemometers were placed at eight equally spaced positions around the outer ring as indicated by the dots. One anemometer was placed at the center of the circle. The size of the array relative to some existing large wind turbines is indicated by the superimposed drawing of wind turbine blades. 
nonmoving locations are derived from any one of the recorded time-sequences of wind velocity. The time-sequences of wind velocity at a point on a turning rotor are obtained by sequentially taking wind velocity values from successive anemometers around the circle. The rate of successive samples is such that the circular path is traversed in the period of rotation of the hypothetical turbine blade.

Another more direct measurement of rotationally sampled wind velocity was made for PNL by the Wave Propagation Laboratory (WPL) at NOAA using a laser anemometer which scanned the wind velocity field in a vertical crosswind circle. A variation of this method was used for measurements made at Colorado State University using hotwire anemometers on a rotating boom. Schematic drawings of the two measurement systems are shown in Figure 3.

Several mathematical descriptions of the Fourier spectrum of the wind velocity seen by a turning rotor of a wind turbine have been developed. Those of Holley, Thresher and Lin [2] and Fichtl (for PNL) utilize homogeneous, isotropic turbulence theory and expansions of the velocity field outward from the hub of a turbine in terms of gradients of wind velocity.

The mathematical model derived here is similar to Rosenbrock's [3]. The new model is an improvement primarily in the use of more realistic Eulerian turbulence wind velocity correlation functions and spectra.

This paper presents new empirical and theoretical descriptions of the spectra of turbulence observed in a rotating frame of reference. All known model spectra are compared with the recently measured spectra. Implications of the results for turbine design, siting and operation are discussed.

Three goals of the research are partially achieved in this paper:

1) Demonstrate the existence and quantitative nature of the distortion of wind velocity variations in time when viewed from a turning blade of a wind turbine rotor

2) Describe turbulence characteristics as seen by a rotating turbine blade at several real wind sites 


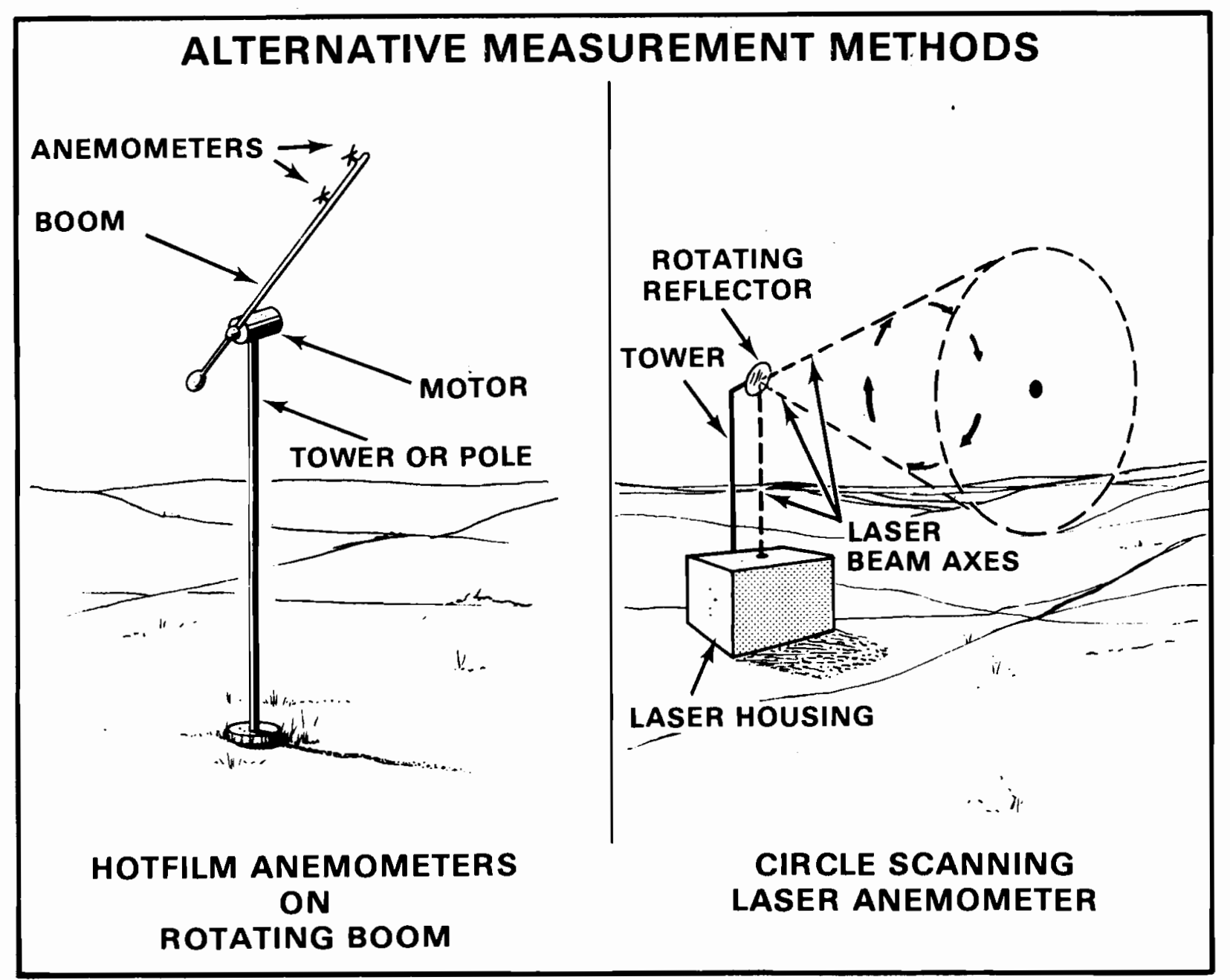

FIGURE 3. Two Methods of Measurement of the Turbulent Wind Observed at a Rotating Blade of a Wind Turbine: a) Hotwire Anemometers on a Boom Which May be Rotated About a Horizontal or a Vertical Axis, and b) a Laser Anemometer Configured to Scan a Truncated Circular Conical Shell Which Approximates the Circular Path of a Point on a Wind Turbine Blade 
3) Provide methods for transforming conventional Eulerian wind characteristics into the wind characteristics experienced by rotating turbine blades. 


\section{WIND SPECTRA MEASURED WITH VERTICAL PLANE ARRAYS OF ANEMOMETERS}

The first PNL vertical plane array consisted of eight wind velocity sensors spaced uniformly in a 24-m diameter circle and one sensor at the center of the circle at a height of $24 \mathrm{~m}$ above the ground. The second vertical plane array at the Hanford field site consisted of the same configuration of anemometers in a 49-m diameter circle whose center was $36 \mathrm{~m}$ above the ground. The terrain at the site is flat and fairly uniformly covered with sagebrush. The height of the sagebrush is about $1 \mathrm{~m}$. The roughness length found from typical mean wind profiles is about $5 \mathrm{~cm}$.

The time increment used in sampling successive anemometers around a circle was $0.1 \mathrm{~s}$ for the small array and $0.2 \mathrm{~s}$ for the large array. This is equivalent to a blade rotation period of $0.8 \mathrm{~s}$ and $1.6 \mathrm{~s}$, respectively. The linear speed of movement of the sampling point, $94 \mathrm{~ms}^{-1}$, is the same for both arrays. The tip speed ratio, $94 \mathrm{~ms}^{-1} \div \bar{U}_{\text {wind }}$, was about 20 for the sma 11 array and 7.6 for the large array. The mean wind blew nearly axially through the disk of the circle. There was very little mean wind velocity component parallel to the plane of the circle.

The spectra of the turbulence normal to the circular disks of each array are shown in Figure 4. The Eulerian wind spectra at the center of the circles are included for reference. The spectra of the rotationally sampled wind show considerable loss of energy in the decade of frequency below the frequency of the largest spike. The largest spike occurs at the frequency of rotation, $n=n_{0}$, and the other spikes occur at frequencies centered about $n=2 n_{0}, 3 n_{0}$, $4 n_{0}$. The average magnitude of the spectra in the region of the spikes is much greater than in the Eulerian spectra. One apparent effect of rotational sampling is to transfer energy at intermediate frequencies to energy at high frequencies and another is to collect a portion of this energy into narrow bands. A third effect, expected at sufficiently high frequencies, is a linear shifting of the high frequency portion of the Eulerian spectrum to a frequency 


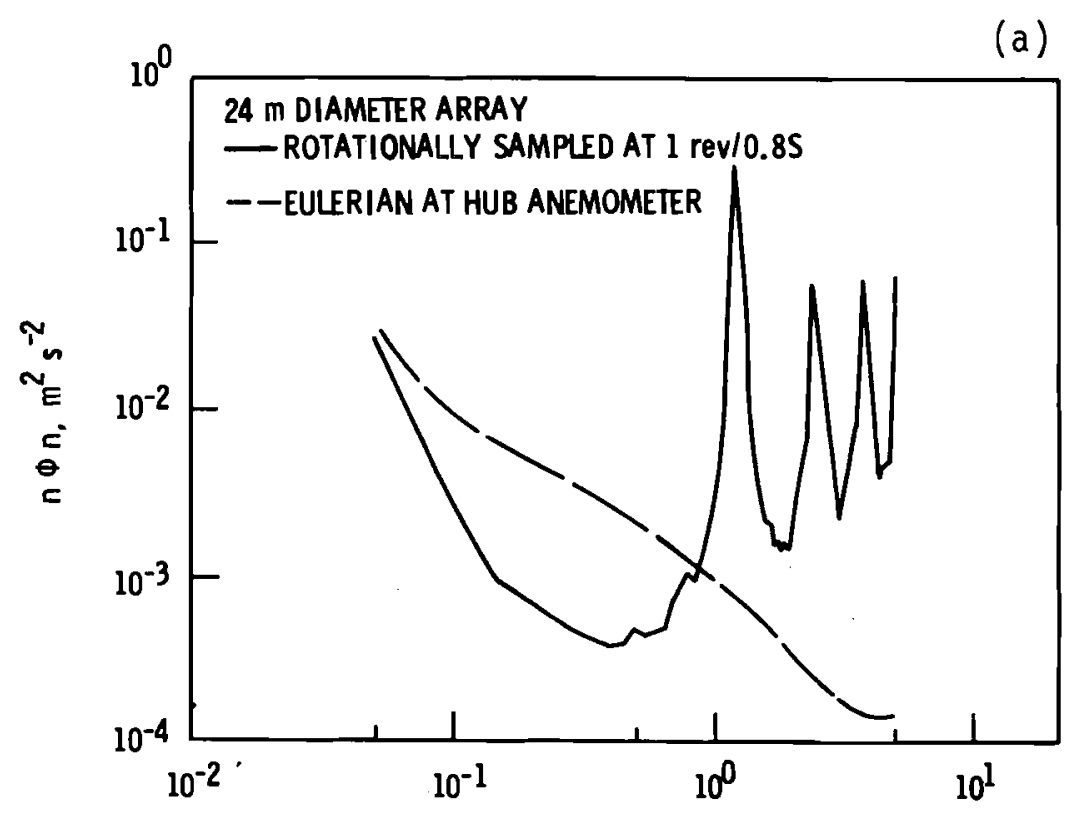

$\mathrm{n}, \mathrm{Hz}$

(b)

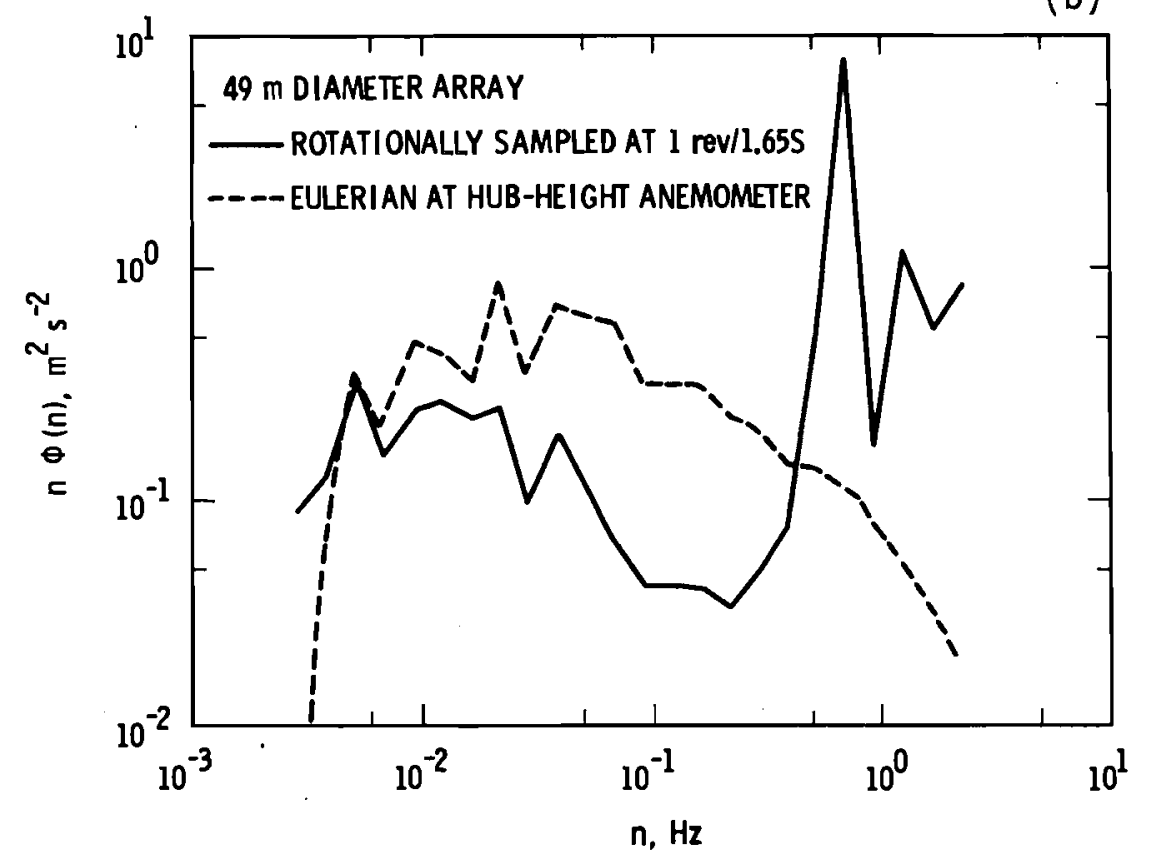

FIGURE 4. Spectra of Wind Fluctuations Derived From Measurements of Wind by Rotationally Sampling Wind Speed Values Around a Circular Array of Anemometers in a Vertical Plane: a) Array Diameter, $D=24 \mathrm{~m}$; Hub Height, $\mathrm{H}=24 \mathrm{~m}$; Period of Rotation, $1 / \mathrm{n}_{0}=0.8 \mathrm{~s}$, Mean Wind Speed, $U=5 \mathrm{~ms}^{-1}$; and Neutral to Slightiy Static Stability; and b) $D=49 \mathrm{~m} ; \mathrm{H}=36 \mathrm{~m} ; 1 / \mathrm{n}_{0}=1.6 \mathrm{~s} ; \mathrm{U}=12 \mathrm{~ms}^{-1}$; and Slightly Stable to Neutral Static Stability. The Eulerian wind speed spectrum at the circle center (hub) height is included for reference. Figure (a) is adapted from Verholek [1]. 
$n^{\prime} \doteq n \cdot V_{T}$, where $V_{T}$ is the tip speed ratio. It would be expected that the total energy of turbulence has not changed by the change of coordinate system.

A comparison of the spectra in Figure 4 shows that the high frequency spikes $\left(n \geq 2 n_{0}\right)$ are proportionally much larger for the small array (24 m diameter) encircled at a frequency of $n_{0}=1.25 \mathrm{~Hz}$, than for the large array (49 m diameter) encircled at a frequency of $n_{0}=0.625 \mathrm{~Hz}$. This difference is related to the length and time scales of the synthesized rotor and of the turbulent wind, and to differences in frequency resolution in the numerical spectral analyses. The former is discussed in Section 4 and Figure 11.

Even the Eulerian spectral estimates shown in Figure 4 have highfrequency slopes which do not follow the slope of isotropic turbulence, which would be expected. This is because no correction to the data was applied for the losses due to finite response time of the anemometers. Polystyrene propellers with an $0.8 \mathrm{~m}$ distance constant were used on the arrays. For the wind speeds observed significant losses occur at frequencies greater than about $0.5 \mathrm{~Hz}$ in the Eulerian coordinate system. It was shown by Connel1 [8] that these effects will be seen in the rotating coordinate system at frequencies which are higher by a factor equal to or greater than the tip speed ratio. This is beyond the spectral spikes and of little importance to a wind turbine.

The transformation from the Eulerian spectrum of the wind velocity to the rotationally sampled wind spectrum is radical as shown by the vertical plane array data. Additional verification experiments were performed using other methods of measurement and diameters of circles for different atmospheric conditions. The results of these experiments are touched upon in the next section. 


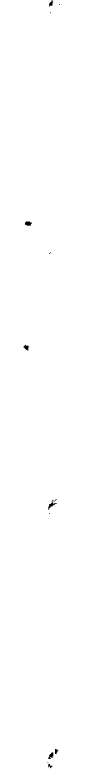




\section{WIND SPECTRA MEASURED WITH LASER AND HOTWIRE ANEMOMETERS SWEEPING THROUGH CIRCULAR CROSSWIND PATHS}

A laser anemometer scanned a circle $10 \mathrm{~m}$ in diameter at a height of $40 \mathrm{~m}$ above slightly rolling terrain near the Boulder Atmospheric Observatory (BAO) meteorological tower near Boulder, Colorado. Wind speeds were light. The static stability (temperature layering) of the atmosphere ranged from unstable to neutral to stable. The circular frequency of rotation was $n_{0}=0.5 \mathrm{~Hz}$, with tip speed ratio $V_{T}=6$. The mean wind speed was about $5 \mathrm{~ms}^{-1}$. The resulting spectra are shown in Figure 5. An Eulerian spectrum of the same through-the-disk component of the wind measured at $50 \mathrm{~m}$ above the ground on the nearby meteorological tower is included for reference on each graph.

The results are similar to those from the $49 \mathrm{~m}$ array at the Pacific Northwest Laboratory for which the tip speed ratio is slightly larger. The lidar data show that even a smal1 diameter $(10 \mathrm{~m})$ rotor rotating slowly $(0.5 \mathrm{~Hz})$ and at relatively great heights above the ground $(H=4$ rotor diameters $=40 \mathrm{~m})$ may experience strong spectral distortions in the turbulence. The lidar data also show different spectral details for each static stability (neutral, unstable, stable) of the boundary layer. The length and time scales of the wind change with changing stability of the boundary layer. The changed scales affect the detailed shape of the spectrum of turbulence seen by the rotating turbine.

At Colorado State University (CSU), a hotwire anemometer was placed upon a $3.8 \mathrm{~m}$ radius boom and rotated at a rate of $0.4 \mathrm{~Hz}$ at a hub height of $6 \mathrm{~m}$ above smooth terrain. Wind velocities were about $2 \mathrm{~ms}^{-1}$ through the disk of rotation, but mean wind speed was not accurately measured. Only two short preliminary experiments have been performed; however, the results indicate that even at a rotor diameter of $7.6 \mathrm{~m}$, the effect of rotational sampling is observed at a tip speed ratio estimated to be between 4 and 9 (see Figure 6 ).

Interpretation of measured distortions of the characteristics of turbulence due to rotational sampling can proceed more fully using the theoretical model and nondimensional parametric analyses developed in the next two sections. 

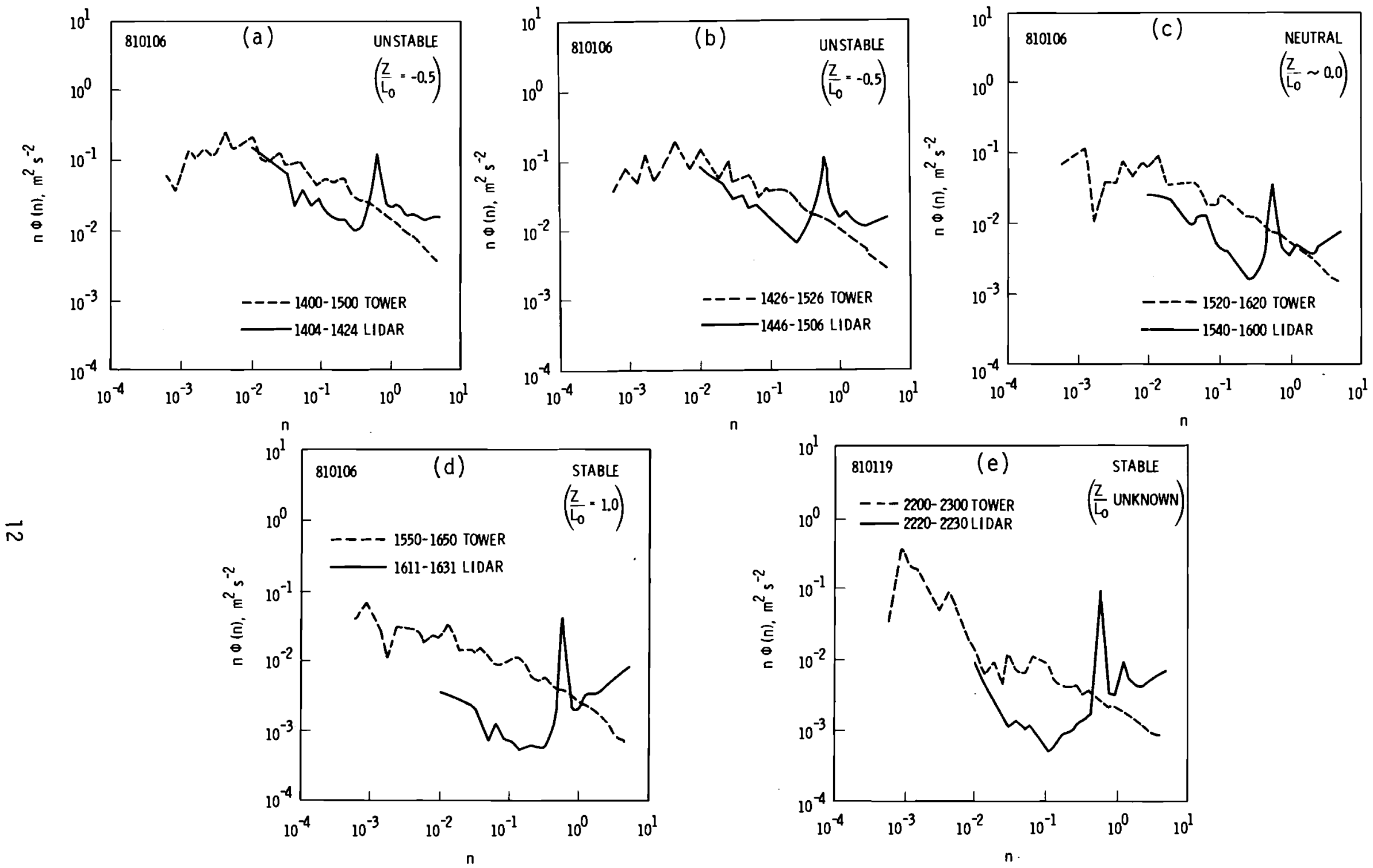

FIGURE 5. Spectra of Axial Wind Speed, U, From Wind Measurements Made by a Laser Anemometer Scanning a Circle in a Vertical Plane: $D=10 \mathrm{~m} ; \mathrm{H}=40 \mathrm{~m} ; 1 / \mathrm{n}_{0}=2.0 \mathrm{~s} ; \bar{U}=5 \mathrm{~ms}^{-1}$. Where known, the stability parameter $z / L_{0}$ is included in the figure. Here, $L_{0}$ is the Monin-Obukov length scale and $z$ is height above ground. The corresponding Eulerian wind speed spectrum, at $50 \mathrm{~m}$ height, from a nearby meteorological tower is placed on each graph for reference. Adapted from work by Hall and Hardesty (see Acknowledgment). 


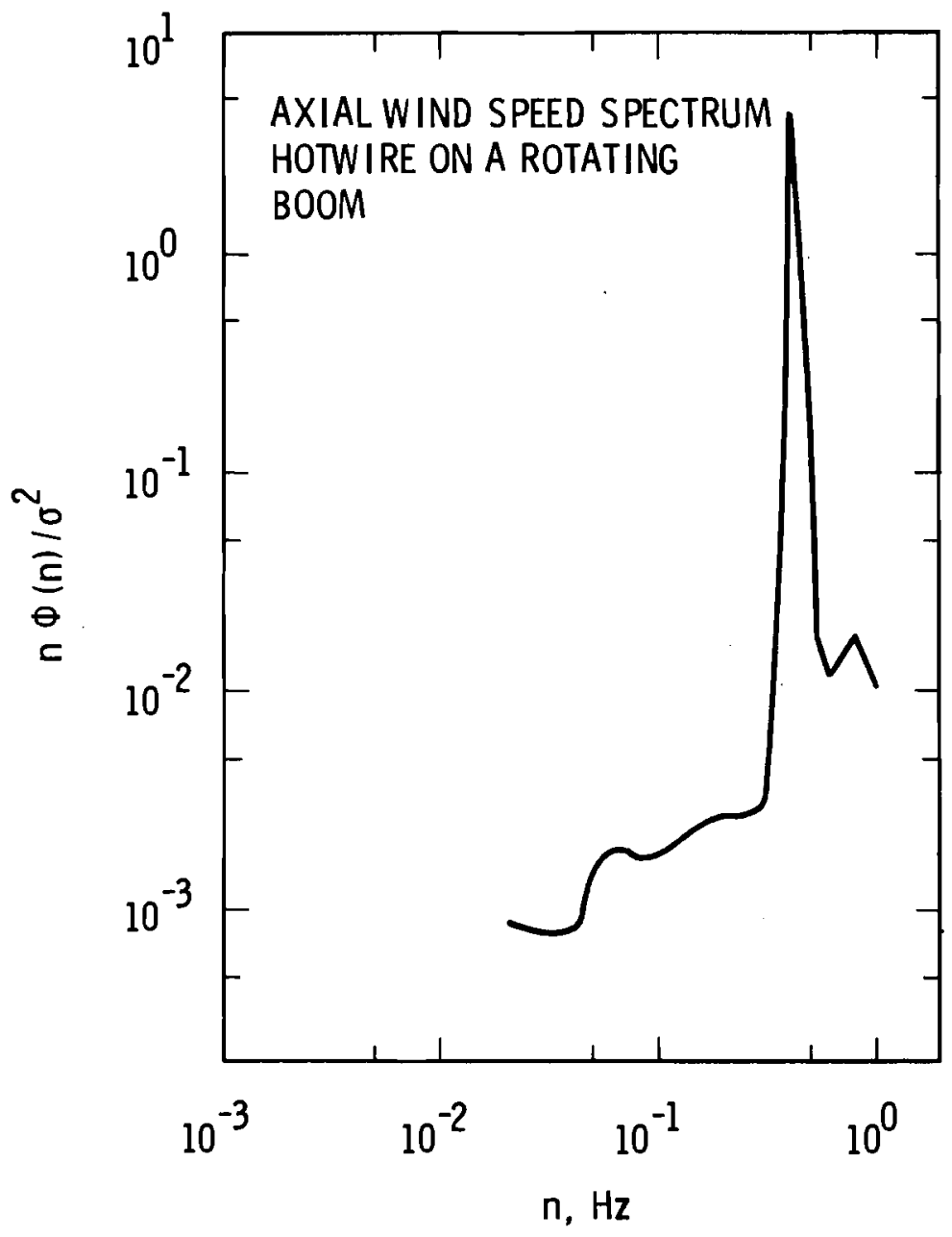

FIGURE 6. Axial Wind Speed Spectrum From Wind Measurements Made by a Hotwire Anemometer Traversing a Circle in a Vertical Plane: $D=7.6 \mathrm{~m}$; $\mathrm{H}=6 \mathrm{~m}, 1 / \mathrm{n}_{0}=2.5 \mathrm{~s} ; \mathrm{U}=2 \mathrm{~ms}^{-1}$, and stable atmosphere. No corresponding spectrum of the measured Eulerian wind is available. Adapted from work by Sandborn (see Acknowledgments). 


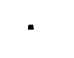

-

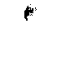


4. A THEORETICAL MODEL OF THE SPECTRUM OF AXIAL TURBULENCE OBSERVED

AT A POINT REVOLVING AROUND A CROSSWIND CIRCULAR PATH

As a point moves around a crosswind circle, it experiences wind velocity fluctuations as a function of time. If measured, this velocity function may be spectrally analyzed. The spectrum can be derived alternatively by Fourier transformation of the space-time correlation function of the turbulence velocity measured in the rotating coordinate system moving with the observation point. This correlation function of space and time is derived from spatial correlations of the same component of turbulence velocity as described below. Figure 7 contains a drawing of the circular path orthogonal to the mean wind direction. As point 2 moves around the circle, cycle after cycle, it will move across the direction of the mean wind. If turbulence fields were frozen and fixed relative to the circle, then a simple relationship would exist between the space-time correlation in the rotating coordinate system and the lateral and longitudinal spatial correlations of the longitudinal component of the turbulence. For homogeneous isotropic turbulence the relation would be

$$
\mathrm{R}_{11}(\tau)=\mathrm{R}_{\ell}[S(\tau)]
$$

where $\tau$ is the time lag between initial position 1 and the current position 2 ,

$S$ is the distance between position 1 and position 2,

$R_{11}(\tau)$ is the autocorrelation function of the axial turbulence velocity $u$ for points 1 and 2 and

$R_{\ell}(S)$ is the lateral spatial correlation of $u$ between points 1 and 2 , where point 1 is fixed.

When point 2 is moving around the circle, the relation between $S$ and $\tau$ is

$$
S=2 \rho \sin \frac{\Omega \pi}{2}
$$




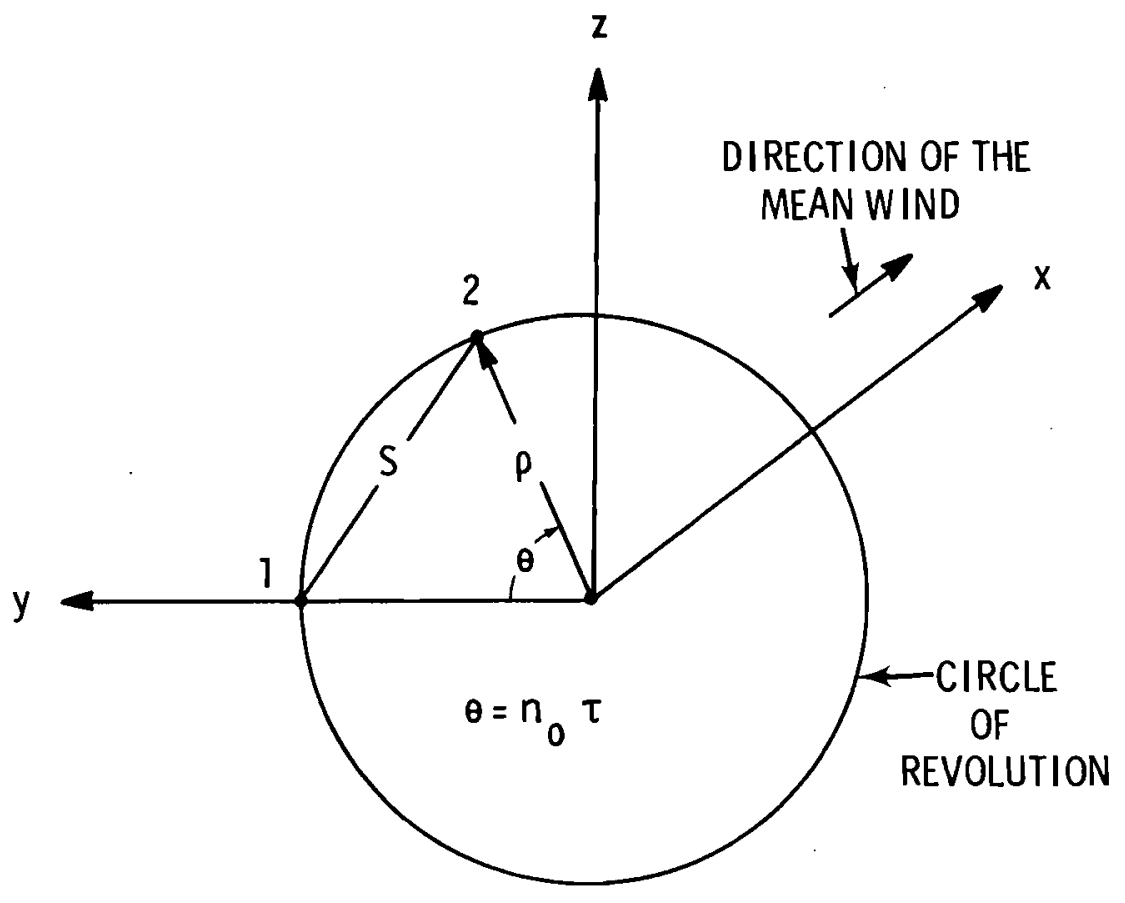

$S / 2=\rho \sin \theta / 2=\rho \sin n_{0} \tau / 2$

FIGURE 7. A Drawing of the Geometry of the Separation Distance, s, for Two Points on the Vertical Circle as a Function of Time, $\tau$. Point 1 is fixed. Point 2 revolves around the circle at a constant frequency, $n_{0}$. The radius of rotation is $\rho$. The wind is blowing axially (in the $x$ direction). The coordinate system is a right-handed one. 
where $\rho$ is the radius of rotation and

$\Omega$ is the angular speed of rotation of the point observed from the center of the circle. It is related to the frequency by $\Omega=2 \pi \mathrm{n}_{0}$.

All realizations of this simple correlation would result in the autocorrelation function labeled $\mathrm{R}_{\ell}(\Omega T / 2)$ in Figure 8 . This is an oscillating correlation function with a period equal to $2 \pi / \Omega$, where $\Omega$ is in radians/s. However, the turbulence eddies are advected through the disk of rotation by the mean wind speed. Thus after long periods of time we would expect the autocorrelation to have a very small magnitude. This magnitude should be that of $R_{a}(x)$, the longitudinal or axial spatial correlation of $u$ transformed to time using Taylor's hypothesis,

$$
x=-\bar{U} \cdot \tau \text {. }
$$

The net result is that

$$
R_{17}(\tau)=f\left\{R_{a}[x(\tau)], R_{\ell}[S(\tau)], \bar{U}, \tau, \Omega, \rho\right\} .
$$

This would appear somewhat as shown by the curve labeled $R_{11}(\tau)$ in Figure 8 . We are without an explicit theoretical formulation for relation (4) in the case of real turbine-size turbulence boundary layers. An empirical relationship is called for in this case. However, for homogeneous, isotropic turbulence, a model may be developed starting with some relationships originated by von Karman [4] as was done by Rosenbrock [3] in 1955.

The turbulence and mean parts of the wind velocity components are defined as follows:

$$
\begin{aligned}
u_{i}= & i^{\text {th }} \text { component of turbulence wind velocity } \\
u_{i}= & u_{i}-\bar{U}_{i} \\
u_{i}= & \text { instantaneous total magnitude of the } i^{\text {th }} \text { component of wind } \\
& \text { velocity and }
\end{aligned}
$$




\section{SCHEMATIC CORRELATION FUNCTION}

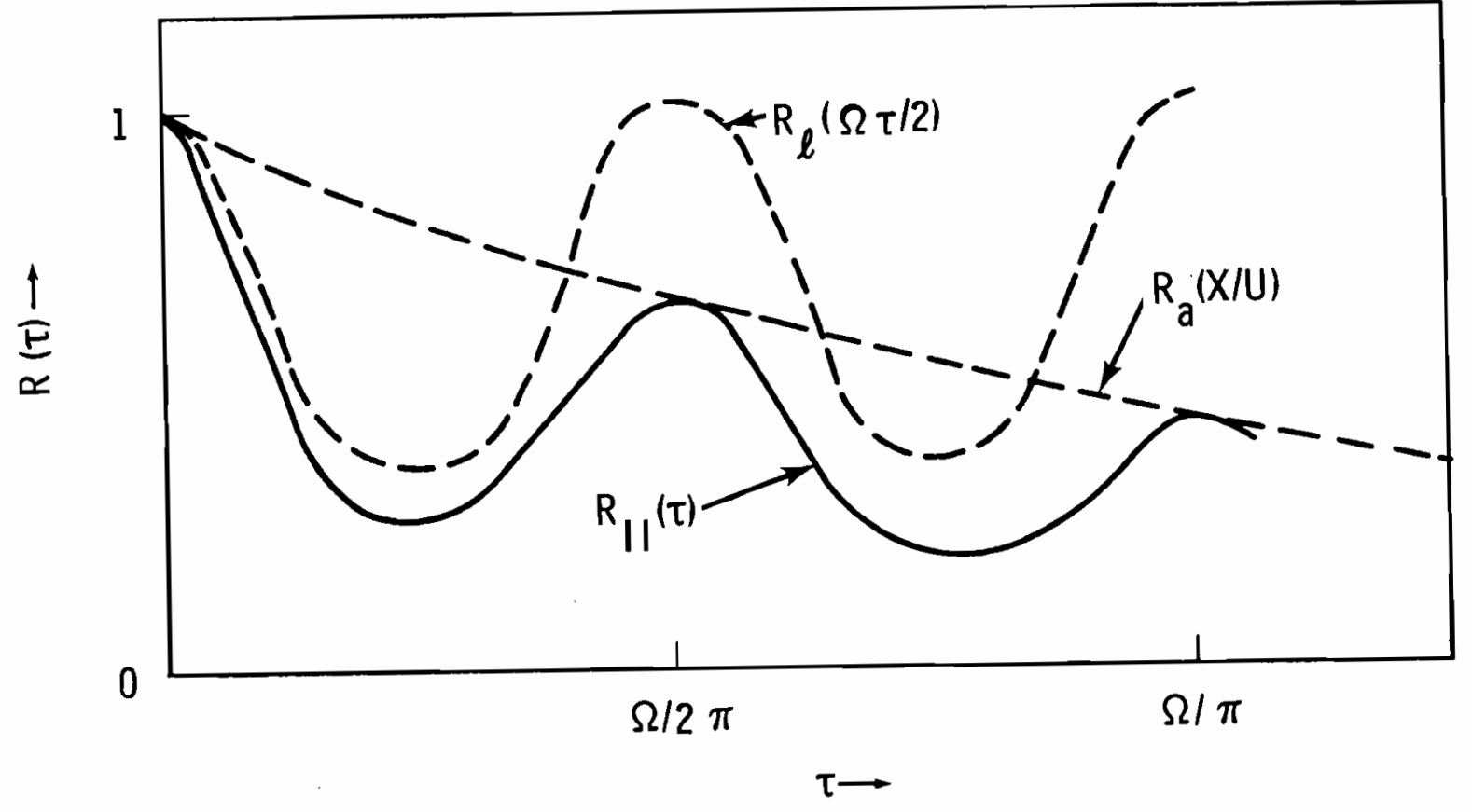

FIGURE 8. Graph Showing the Expected Form of the Two Point-Time Lag Correlation of Axial Wind Speed Between Points 1 and 2 Based Upon Simple Physical Reasoning Given in the Text 


$$
\begin{aligned}
\bar{U}_{i}= & \text { ensemble average or time average of the } i^{\text {th }} \text { component of wind } \\
& \text { velocity. }
\end{aligned}
$$

The correlation tensor is defined as

$$
R_{i j}=\overline{u_{i} u_{j}} \text { for } i, j=1,2,3 \text {. }
$$

For homogeneous, isotropic turbulence this tensor may be written in alternative notation as

$$
\overrightarrow{\vec{R}}=\frac{R_{a}-R_{\ell}}{r^{2}}\left(\begin{array}{ccc}
x^{2} & x y & x z \\
y x & y^{2} & y z \\
z x & z y & z^{2}
\end{array}\right)+R_{\ell}\left(\begin{array}{lll}
1 & 0 & 0 \\
0 & 1 & 0 \\
0 & 0 & 1
\end{array}\right)
$$

where

$$
\begin{aligned}
x^{2}+y^{2}+z^{2}= & r^{2} \text { is the square of the separation distance between } \\
& \text { the two points of correlation } \\
R_{a} & \text { is the spatial correlation between } \vec{r} \text { components of } \\
& \text { the turbulence velocity at the variable separation } \\
& \text { distance } r \text {, or the double longitudinal correlation } \\
& \text { for homogeneous, isotropic turbulence } \\
R_{\ell} & \text { is the spatial correlation between coplanar components } \\
& \text { of the turbulence velocity which is perpendicular to } \\
& \vec{r} \text { at the variable separation distance } \vec{r} \text {, or the } \\
& \text { double lateral correlation in homogeneous isotropic } \\
& \text { turbulence. }
\end{aligned}
$$

Von Karman [4] also showed that for homogeneous isotropic turbulence

$$
R_{\ell}=R_{a}+\frac{r}{2} \frac{d R_{a}}{d r} \text {. }
$$

Using the notation in Figure 7 , with the origin translated to the point on the $y$ axis and the circle,

$$
\vec{r}^{2}=x^{2}+y^{2}+z^{2}=x^{2}+s^{2} .
$$


The next step is to transform $r^{2}$ to a function of time $1 \mathrm{ag}, \tau$, by using relations (2) and (3) in (8). This gives

$$
\vec{r}^{2}=(-U \tau)^{2}+\left(2 \rho \sin \frac{\Omega \tau}{2}\right)^{2} .
$$

Consider only the wind fluctuations in the direction of the mean wind, $u_{i}=u$. Since the present purpose is to develop a theoretical model equivalent to observations of spectra of the u component of turbulence, we can ignore the crosswind turbulence components. The two point correlation of the axial wind velocity is defined as

$$
\begin{aligned}
R_{11}= & \overline{u\left(x_{1}\right) u\left(x_{2}\right)}, \\
& \text { or from eqn. (6) } \\
R_{11}= & \frac{R_{a}-R_{\ell}}{r^{2}}\left(\begin{array}{lll}
x^{2} & 0 & 0 \\
0 & 0 & 0 \\
0 & 0 & 0
\end{array}\right)+R_{\ell}\left(\begin{array}{lll}
1 & 0 & 0 \\
0 & 0 & 0 \\
0 & 0 & 0
\end{array}\right) \\
R_{11}= & R_{a}(r) \frac{x^{2}}{r^{2}}+R_{\ell}(r)\left(1-\frac{x^{2}}{r^{2}}\right) .
\end{aligned}
$$

For isotropic homogeneous turbulence von Karman [4] (see also Holley, Thresher and Lin [2]) showed that

$$
R_{a}(r)=\frac{2}{\Gamma(1 / 3)} \sigma^{2}\left[\frac{r}{2 L}\right]^{1 / 3} K_{1 / 3}\left(\frac{r}{L}\right) \text {. }
$$

Then

$$
R_{\ell}(r)=\frac{2}{i(1 / 3)} \sigma^{2}\left[\frac{r}{2 L}\right]^{1 / 3}\left[K_{1 / 3}\left(\frac{r}{L}\right)-\frac{r}{2 L} K_{2 / 3}\left(\frac{r}{L}\right)\right]
$$

where $L=$ an integral length scale of turbulence

$$
\sigma^{2}=\text { variance of } u
$$




$$
\begin{aligned}
\Gamma= & \text { the gamma function and } \\
K_{v}= & \text { the modified Bessel function of the second kind of } \\
& \text { fractional order, } v .
\end{aligned}
$$

Substituting eqn. (12) and (13) into eqn. (11) gives

$$
\mathrm{R}_{11}=\frac{2}{\Gamma(1 / 3)} \sigma^{2}\left(\frac{r}{2 L}\right)^{1 / 3}\left\{K_{1 / 3}\left(\frac{r}{L}\right)-\frac{r}{2 L}\left[1-\frac{x^{2}}{r^{2}}\right] K_{2 / 3}\left(\frac{r}{L}\right)\right\} .
$$

The two-point, time-lag correlation of the axial fluctuation of wind speed observed by a point revolving on a circle at constant speed is obtained by substituting eqns. (3) and (9) into eqn. (14).

The spectral density of $u^{2}$ which corresponds to the correlation in eqn. (14) can be obtained by a Fourier integral transformation. Since $R_{11}(\tau)$ is an even function, the transformation may be written as follows:

$$
\phi_{11}(n)=2 \int_{0}^{\infty} R_{11}(\tau) \cos (2 \pi n \tau) d \tau
$$

where $n=$ spectral frequency, hertz and

$\tau=$ time lag.

In order to collapse the correlation functions and corresponding spectral density functions for many conditions into a single function, a nondimensional formulation is required. The tip speed ratio, $\lambda_{T}$, is often used in rotor design and analysis. It is defined here as follows:

$$
\lambda_{\mathrm{T}}=\frac{\rho \Omega}{\bar{U}}
$$

If the distance, $r$, is nondimensionalized by the integral length scale of turbulence, L, eqn. (9) becomes

$$
\frac{r^{2}}{L^{2}}=L^{-2}\left[(\bar{U} \tau)^{2}+4 \rho^{2} \sin ^{2}\left(\frac{\Omega \tau}{2}\right)\right]^{1 / 2} \text {. }
$$


Further, using relations (3) and (9) in

$$
1-\frac{x^{2}}{r^{2}}=\frac{s^{2}}{r^{2}}
$$

and relation (16), we have

$$
1-\frac{x^{2}}{r^{2}}=\frac{4 \rho^{2} \sin ^{2} \frac{\Omega \tau}{2}}{\left(\frac{\rho \Omega \tau}{\lambda}\right)^{2}+4 \rho^{2} \sin ^{2}\left(\frac{\Omega \tau}{2}\right)} \text {. }
$$

Two other nondimensional variables fall naturaliy from eqns. (16) and (17):

$$
\frac{\Omega \tau}{2}=T
$$

and

$$
\underline{\rho}=P
$$

In nondimensional form eqns. (17) and (18) are

$$
\frac{r}{L}=2\left[\left(\frac{P}{\lambda_{T}}\right)^{2} T^{2}+P^{2} \sin ^{2} T\right]^{1 / 2}
$$

and

$$
1-\frac{x^{2}}{r^{2}}=\frac{\lambda_{T}^{2} \sin ^{2} T}{T^{2}+\lambda_{T}^{2} \sin ^{2} T} \text {. }
$$

Placing eqns. (21) and (22) in eqn. (14), the nondimensional two-point, time-lag correlation function, $R_{11}(T)$, is written in final form as follows:

$$
\begin{aligned}
& \frac{R_{11}(T)}{\sigma^{2}}=\frac{2}{\Gamma(1 / 3)}\left[\left(\frac{P}{\lambda_{T}}\right)^{2} T^{2}+P^{2} \sin ^{2} T\right]^{1 / 6}\left\{K_{1 / 3}\left[2\left[\left(\frac{P}{\lambda_{T}}\right)^{2} T^{2}+P^{2} \sin ^{2} T\right]^{1 / 2}\right]\right. \\
& \left.-\left[\left(\frac{P}{\lambda_{T}}\right)^{2} T^{2}+P^{2} \sin ^{2} T\right]^{-1 / 2} P^{2} \sin ^{2} T K_{2 / 3}\left[2\left[\left(\frac{P}{\lambda_{T}}\right)^{2} T^{2}+P^{2} \sin ^{2} T\right]^{1 / 2}\right]\right\} .
\end{aligned}
$$


Substituting the expression for $\tau$ from eqn. (19) into eqn. (15) the nondimensional spectral density transform becomes

$$
\frac{\phi_{11}(n)}{\sigma^{2}}=\frac{4}{\Omega} \int_{0}^{\infty} \frac{R_{11}(T)}{\sigma^{2}} \cos (2 \pi N T) d T
$$

where

$$
N=\frac{2 n}{\Omega}
$$

Equations (23) and (24) represent the new model. The integration is performed by finite summations using series expansions for $k_{1 / 3}$ and $k_{2 / 3}$ given in references [5], [6], [7].

The improvement of the present model for $\mathrm{R}_{11}$ and $\phi_{11}$ over the Rosenbrock model is in the use of the von Karman correlation functions given in eqn. (12) and (13). Rosenbrock used

$$
R_{a}=\sigma^{2} e^{-\left(r^{2} / L^{2}\right)}
$$

and

$$
R_{l}=\left(1-\frac{r^{2}}{L^{2}}\right) \sigma^{2} e^{-\left(r^{2} / L^{2}\right)} .
$$

The two expressions for $R_{a}$ given in eqns. (12) and (25) are compared in the graph in Figure 9. The corresponding expression for $R_{\ell}$ are also compared in the figure. It would appear that Rosenbrock's analysis should give a qualitatively correct spectral density function. It is replotted in frequency weighted form using log-log coordinates in Figure 10(a). A spectral density function from the new model is shown in Figure 10(b). In Rosenbrock's computation, $\mathrm{n}_{0}==0.48 \mathrm{~Hz}, \mathrm{~L}=100 \mathrm{~m}$ and $\bar{U}=17 \mathrm{~ms}^{-1}$; for the new case, $\mathrm{n}_{0}=0.625 \mathrm{~Hz}$, $L=100 \mathrm{~m}$ and $\bar{U}=10 \mathrm{~ms}^{-1}$. The comparison is qualitatively good. The real value of the model is that it provides verification of the observed effect of rotational sampling independent of the measurements reported in this paper. 


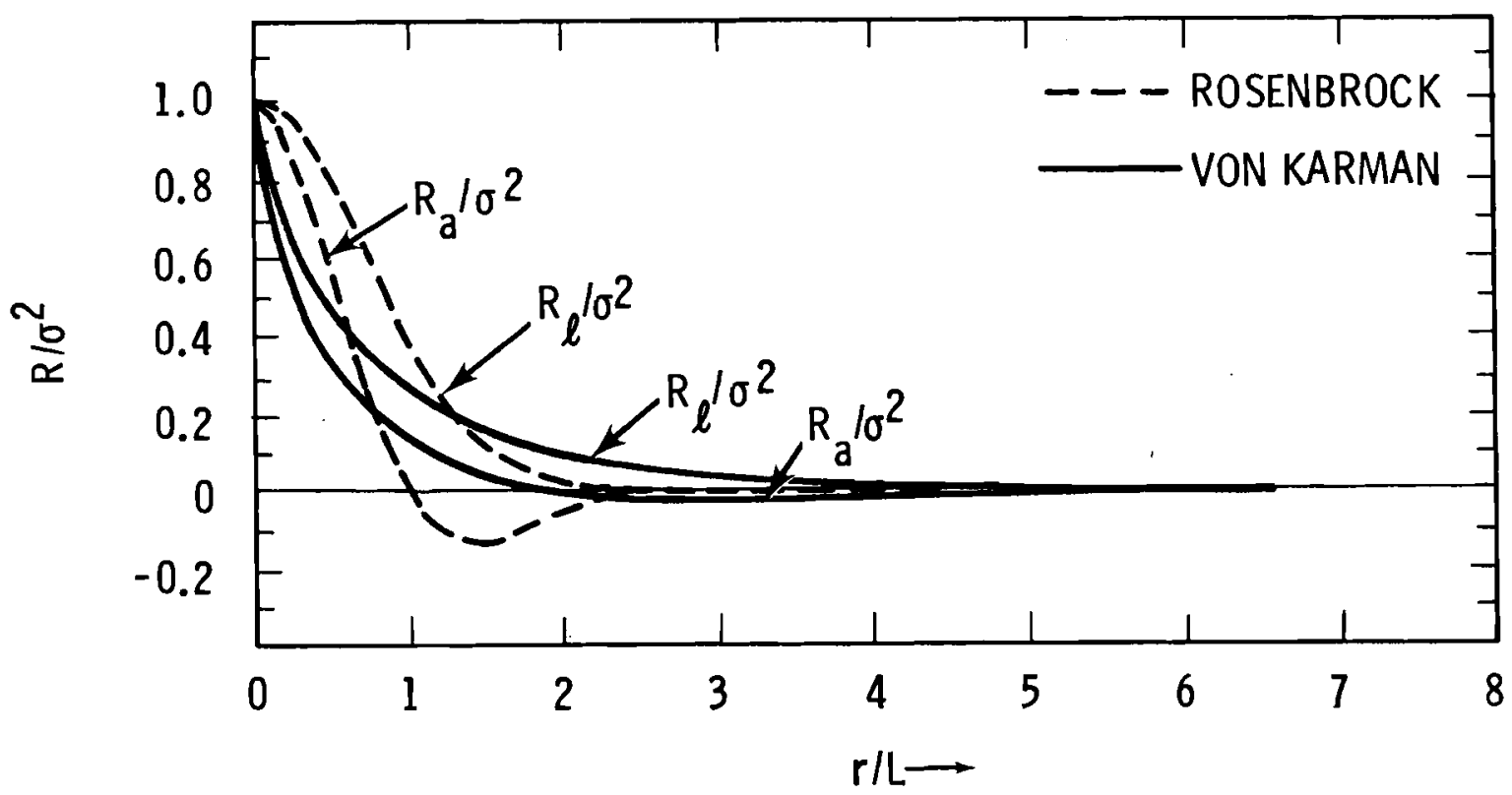

FIGURE 9. A Comparison of Two Double Spatial Correlation Functions of the Wind Speed in the Mean Wind Direction: a) Rosenbrock's [3] Exponential Form; b) von Karman's [4,2] Form for Isotropic Turbulence. 


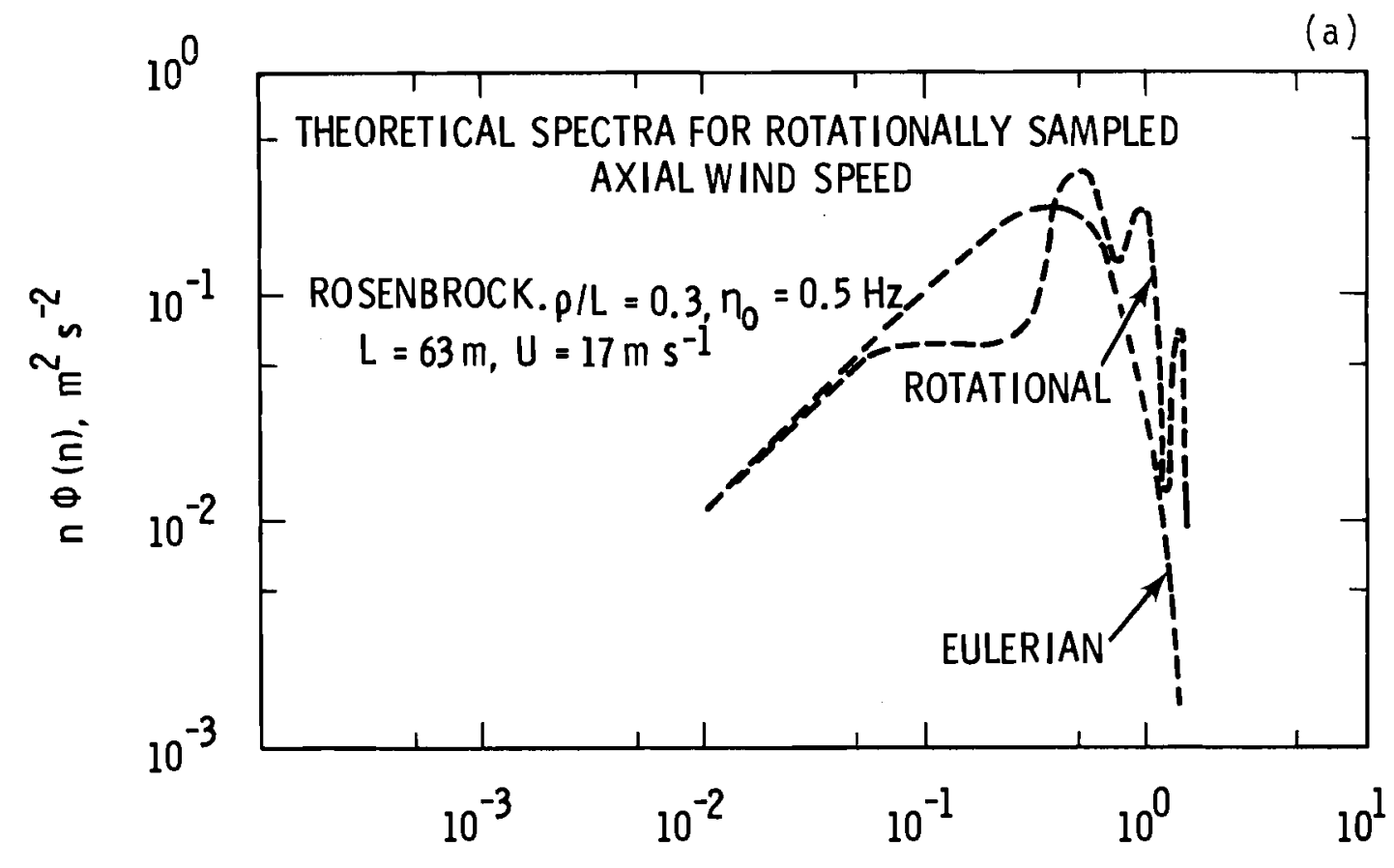

n, $\mathrm{Hz}$

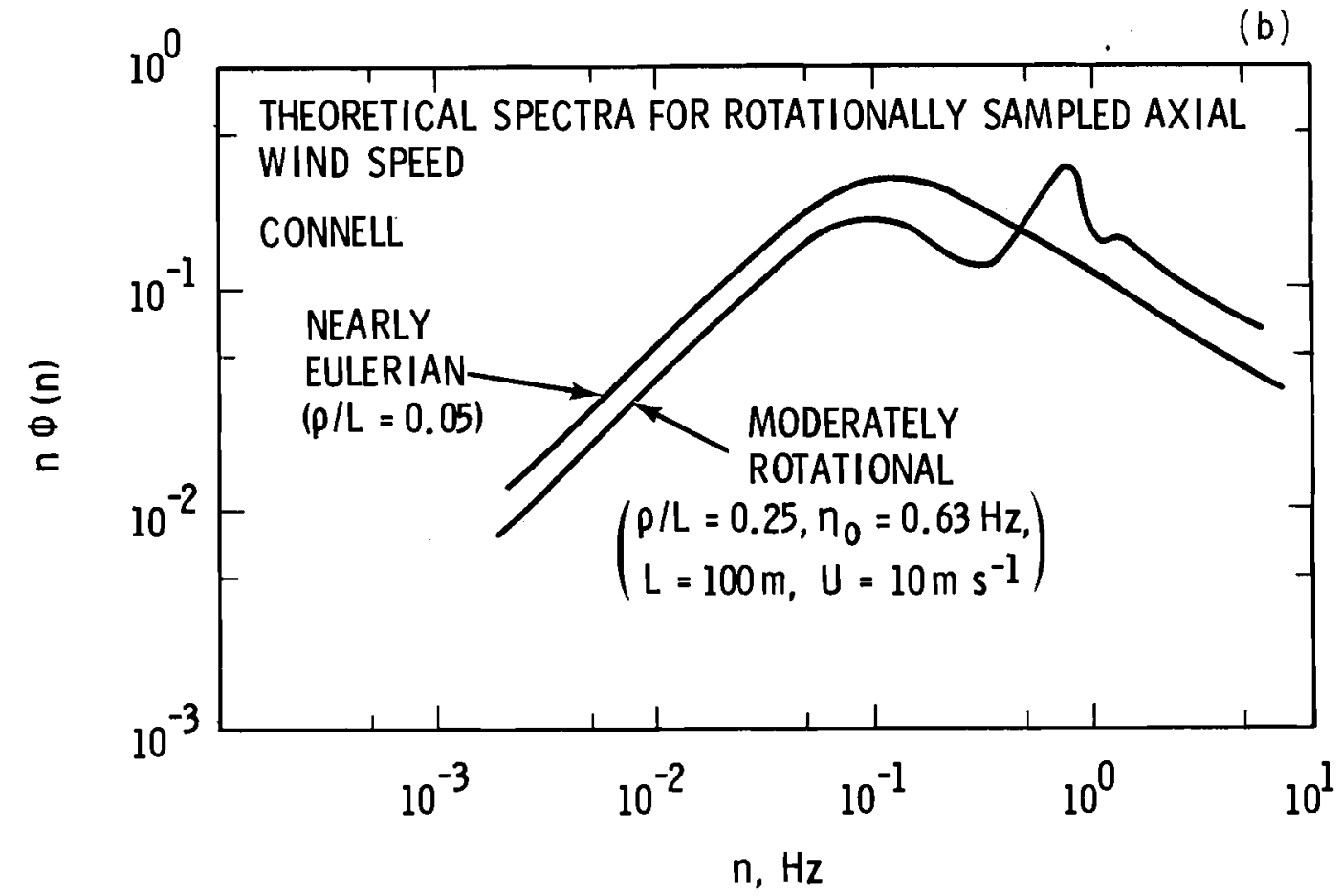

FIGURE 10. Plots of the Wind Speed Spectra for Rotationally Observed Wind Derived From the Formulas of a) Rosenbrock and b) Conne11. The corresponding Eulerian spectra are plotted with dashed 7 ines.

Figure (a) is adapted from Section 4.3.1, Figure 2 in reference [3]. 
Figure 11 shows the new model spectrum for several values of $\bar{U}, \rho, \Omega$, and $L$, or of the nondimensional variables $T$ and $P$. The parametric variation of the spectrum is given in terms of the nondimensional ratios $P=\rho / L$ and $P / \lambda_{T}=$ $(\bar{U} / L) / n_{0}=N_{\text {turbulence }} / n_{0}$ turbine, where $\lambda_{T}$ is the tip speed ratio of the blade rotation, $\bar{U}$ is the mean wind speed, $L$ is a measure of the integral scale of turbulence and $\mathrm{N}_{\text {turbulence }}$ is a measure of the cyclical frequency with which the largest turbulence eddies turn over. The relative magnitude of spikes in the spectrum at $n>n_{0}$ depends strongly on turbine geometry and kinematics as well as turbulence properties. The dependence of the shape of the observed spectrum of turbulence on these properties is discussed further in the next section. 


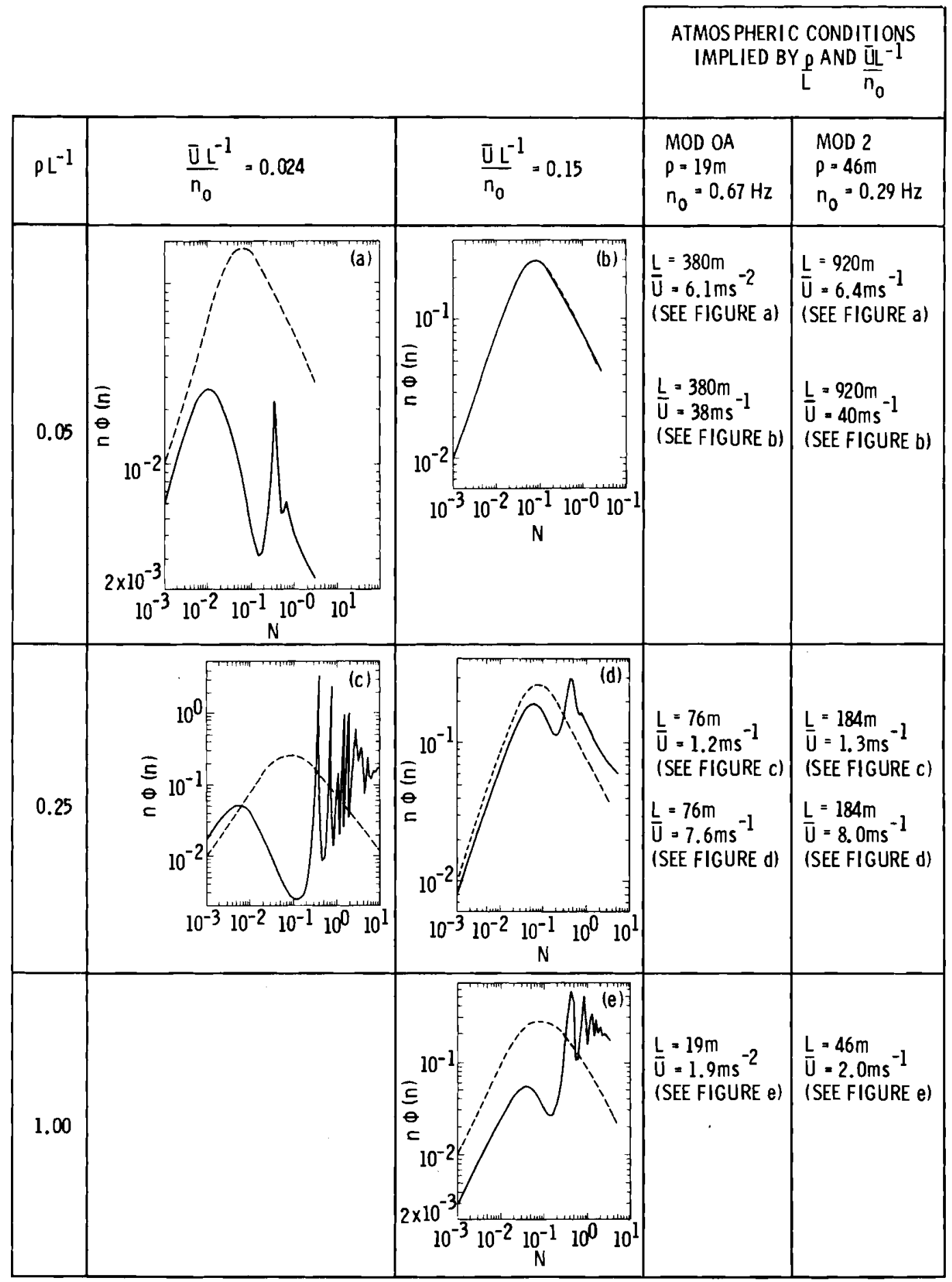

FIGURE 11. A Family of Spectra for the Axial Wind Sampled Rotationally in a Circle in the Crosswind Plane, Derived From the New Formulation by Connell. The spectra, weighted by the frequency in hertz, $n$, are plotted on $\log$ graphs against the nondimensional frequency $N=\frac{\Omega n}{2}$. 


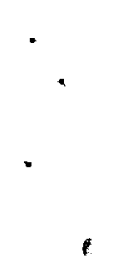

. 


\section{SCALING}

In an earlier report [8], physical reasoning was used to show that the difference between the spectrum of the Eulerian wind and the spectrum of rotationaliy sampled wind depended upon two nondimensional parameters. If there are significant differences between Eulerian and rotational wind speed spectra, the following inequalities must hold for nonisotropic turbulence:

$$
P=\frac{\rho}{L_{T}}>\alpha_{1}
$$

and

$$
\lambda_{T} \frac{L_{L}}{L_{T}}=\left(\frac{\rho \Omega}{\bar{U}}\right)\left(\frac{L_{L}}{L_{T}}\right)>a_{2}
$$

where $\alpha_{1}$ and $\alpha_{2}$ are constants and $L_{L}$ and $L_{T}$ are longitudinal and transverse scales of turbulence.

It was concluded that a wind turbine with a diameter of $4 \mathrm{~m}$ would not experience spectrally distorted turbulence but that a 24-m diameter turbine such as the Danish wind turbine, the Gedser mi11, would. The new theoretical model gives an analytic relation between $P$ and $\lambda_{T}$ and the autocorrelation functions, which permits a more accurate discussion of scaling. Several conclusions about the scale dependence of spectral redistribution due to rotational sampling are given in Table 1 . 
TABLE 1. Scale Dependence of Rotational Sampling Modifications of Turbulence Spectra

\begin{tabular}{|c|c|}
\hline $\begin{array}{c}\text { Physical Reasoning } \\
\text { (Connel1 1980) }\end{array}$ & $\begin{array}{c}\text { Analytic Reasoning Using the } \\
\text { Connell Mathematical Model }\end{array}$ \\
\hline $\begin{array}{l}\text { Rotational sampling effects } \\
\text { diminish as } \mathrm{\rho} / \mathrm{L} \text { decreases } \\
\text { ( } \rho=\text { rotor radius, } L=\text { length } \\
\text { scale of turbulence). }\end{array}$ & $\begin{array}{l}\text { Spectral distortion in the } \\
\text { revolving frame of reference } \\
\text { diminishes as } \rho / L(=P) \text { decreases } \\
\text { and } P / \lambda_{T}(=\bar{U} / \Omega L) \text { remains } \\
\text { constant. }\left[B y \text { eqn. }(23), R_{11}(T) / \sigma^{2}\right. \\
\text { approaches the magnitudes of } \\
\text { the Eulerian autocorrelation.] }\end{array}$ \\
\hline $\begin{array}{l}\text { Rotational sampling effects } \\
\text { increase as } \lambda_{T} \text { increases } \\
\left(\lambda_{T}=\text { tip speed ratio, } \frac{\Omega \rho}{\bar{U}}\right) \text {. }\end{array}$ & $\begin{array}{l}\text { Spectral distortion in the } \\
\text { revolving frame of reference } \\
\text { increases as } \lambda_{T} \text { increases. The } \\
\text { sinusoidal terms in } R_{11}(T) / \sigma^{2} \\
\text { become larger than the } T^{2} \text { terms } \\
\text { in eqn. (23). }\end{array}$ \\
\hline $\begin{array}{l}\text { The total energy of turbulence } \\
\text { is the same in the revolving } \\
\text { frame (at any } \Omega, \text { o) as in the } \\
\text { Eulerian frame of reference, } \\
\text { neglecting effects of mean wind } \\
\text { shear. }\end{array}$ & $\begin{array}{l}\text { The total energy of turbulence } \\
\text { is proportional to } \sigma^{2} \text {. This is } \\
\text { also equal to } R_{11}(T) \text { at } T=0 \text {. } \\
\text { Thus } \sigma^{2} \text { is not a function of } \lambda_{T} \\
\text { or } P \text { (for homogeneous, isotropic } \\
\text { turbulence). In the real atmo- } \\
\text { spheric boundary layer a more } \\
\text { correct statement is that } \sigma^{2} \text { is } \\
\text { not a function of } \Omega \text { or } \rho \text {. }\end{array}$ \\
\hline
\end{tabular}




\section{COMPARISON OF THEORETICAL SPECTRA WITH MEASURED SPECTRA}

Four theoretical functions representing the u spectrum of the rotationally sampled wind are known. A1l four were derived for isotropic, homogeneous turbulent wind. They are all asymptotic to the Eulerian spectrum at low spectral frequencies and are depleted in the midfrequency region. A11 have an excess of energy in a narrow band around the $n_{0} \equiv \frac{\Omega}{2 \pi}$ frequency. The Rosenbrock and Connel1 models produce excess energy at frequencies greater than $n_{0}$ (Figure 10). These two models also have energy spikes at multiples of the frequency $n_{0}$. They qualitatively predict all of the features observed in the spectra measured for turbulence observed in the rotating frame of reference. The Fichtl and Holley model computations (Figure 12) do not reproduce an energy excess at frequencies greater than $n_{0}$. The models are tested for the first time in this work.

Very few data exist by which to perform an adequate quantitative test of the theories. However, one available feature of the spectra would appear to be fairly stable over the range of conditions observed to date, i.e., the ratio of the frequency of rotation, $n_{0}$, to the frequency at which the local minimum, $n_{d}$, occurs in the region of energy depletion (see Figure 13). The several theoretical spectra and observations of real wind spectra are compared in Table 2. The magnitude of $n_{0} / n_{d}$ for the theoretical spectra by Rosenbrock, Holley and Connell compare well with each other. In Fichtl's model, $n_{0} / n_{d}$ is three to four times larger. They also compare reasonably well with the measured turbulence spectra under neutral and unstable static stabilities (temperature layering of the atmosphere). The observations taken during stable stratification of the boundary layer do not agree with the existing isotropic theories of spectra in the rotating frame of reference. Several observed spectra are plotted on the same graph with two results from Connell's model in Figure 14. The mode1 shows all features of the observations at the correct frequencies. However, the magnitude of the energy in the fluctuations is greater in the measured wind spectra which include nonisotropic and inhomogeneous effects. 


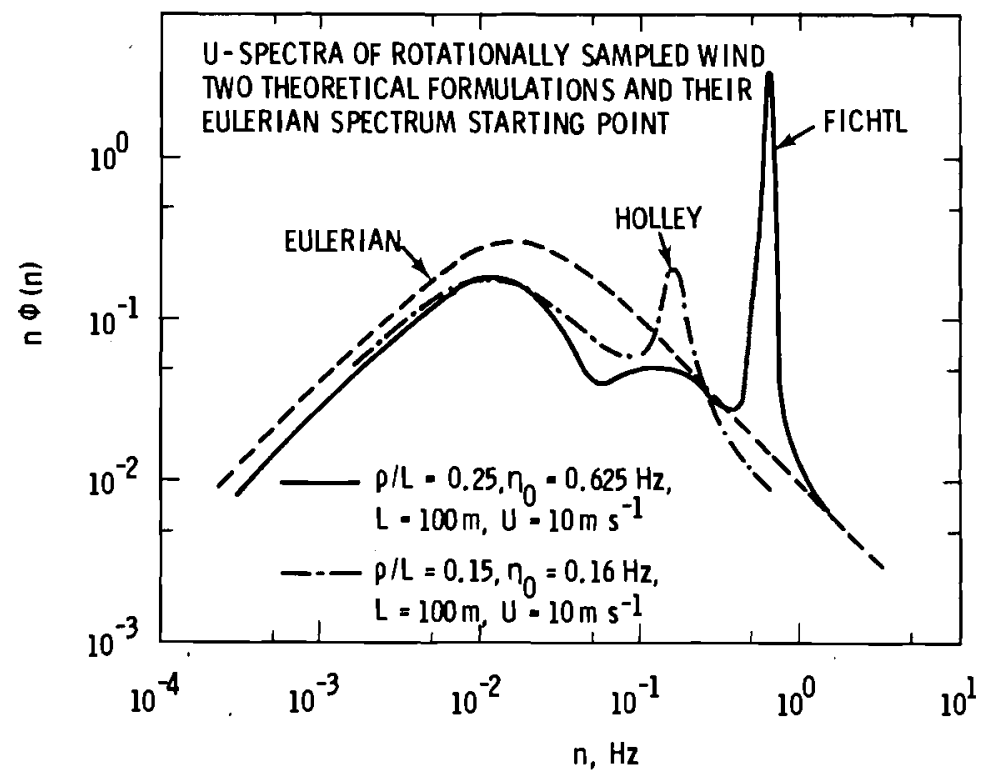

FIGURE 12. Plots of the Wind Speed Spectra for Rotationally Observed Wind Adapted From a) Holley and b) Fichtl (see Acknowledgments)

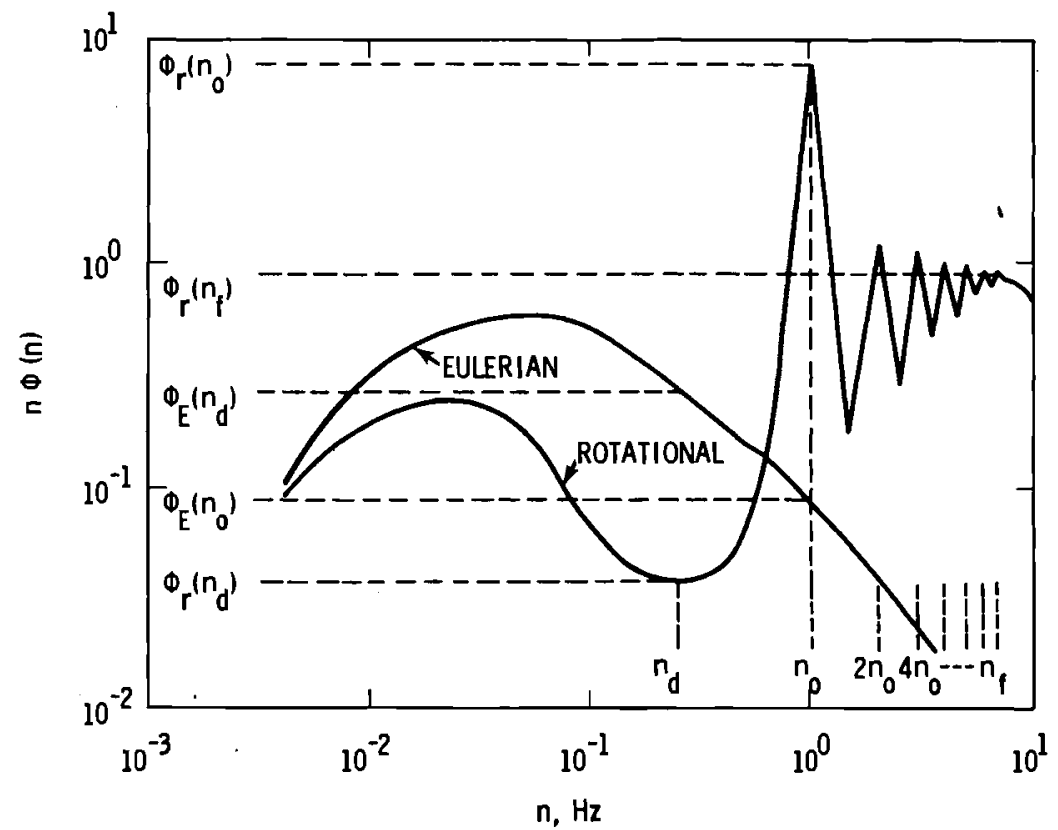

FIGURE 13. Universal Features of the Spectrum of Rotationally Sampled Wind and the Corresponding Nomenclature

where $n_{d}=$ circular frequency of midfrequency spectral minimum

$n_{0}=$ circular frequency of rotation of the blade

$n_{f}=$ frequency of highest observed spike in the spectrum

$\phi_{E}(n)=$ value of Eulerian spectrum at frequency, $n$

$\phi_{r}(n)=$ value of rotational sampled wind spectra at frequency, $n$. 
TABLE 2. Comparison of Theory and Observations of Wind Spectra

\begin{tabular}{|c|c|c|c|c|c|c|c|c|}
\hline & $\begin{array}{c}D \\
(m)\end{array}$ & $\begin{array}{c}\mathrm{H} \\
(\mathrm{m}) \\
\end{array}$ & $\begin{array}{c}\bar{U}_{H} \\
\left(\mathrm{~ms}^{-1}\right) \\
\end{array}$ & $\begin{array}{c}n_{0} \\
(H z) \\
\end{array}$ & $\begin{array}{c}\mathrm{V}_{\mathrm{T}} \\
\left(2 \pi n_{0 \rho} / \overline{\mathrm{U}}\right) \\
\end{array}$ & $\mathrm{D} / \mathrm{L}^{+}$ & $\mathrm{n}_{0} / \mathrm{n}_{\mathrm{d}}$ & Stability \\
\hline \multicolumn{9}{|l|}{ Theory } \\
\hline Rosenbrock & 38 & & 17 & 0.5 & 3.5 & $0.6 \frac{1}{t}$ & 2.0 & Isotropic \\
\hline Fichtl & 50 & & 10 & 0.6 & 9.4 & 0.5 & $1.6,11$ & Isotropic \\
\hline Holley & 50 & & 10 & 0.5 & $\approx 7.9$ & 0.5 & 2.2 & Isotropic \\
\hline Connell & 50 & & 10 & 0.67 & 10.5 & 0.5 & 2.1 & Isotropic \\
\hline \multicolumn{9}{|l|}{ Observation } \\
\hline \multirow{3}{*}{$\begin{array}{l}\text { Conne11 } \\
\text { PNL (VPA)* }\end{array}$} & \multirow{3}{*}{50} & \multirow{3}{*}{36} & \multirow{3}{*}{12.3} & & \multirow{3}{*}{$\begin{array}{l}7.7 \\
3.8 \\
\end{array}$} & \multirow{3}{*}{$\begin{array}{l}0.6 \\
0.6 \\
\end{array}$} & & \\
\hline & & & & 0.6 & & & 3 & \multirow{2}{*}{$\begin{array}{l}\text { Slightly } \\
\text { Stable to } \\
\text { Neutral }\end{array}$} \\
\hline & & & & 0.3 & & & 3 & \\
\hline \multirow[t]{5}{*}{ WPL (1 aser) } & \multirow[t]{5}{*}{10} & 40 & 5.4 & 0.5 & 6.8 & 0.125 & 2.4 & Unstable \\
\hline & & 40 & 4.7 & 0.5 & 5.9 & 0.125 & 2.4 & Unstable \\
\hline & & 40 & 4.7 & 0.5 & 5.9 & $\sim 0$ & 2.4 & Neutral \\
\hline & & 40 & 4.5 & 0.5 & 5.6 & 0.25 & 4.6 & Stable \\
\hline & & 40 & 5.5 & 0.5 & 6.9 & 0.25 & 6.0 & Stable \\
\hline CSU (hotwire) & 7.6 & 6 & 2 & 0.4 & 4 to 9 & $1.3^{5}$ & $1.6,10.5$ & Stable \\
\hline
\end{tabular}

$+L=\int_{0}^{\infty} f\left(x_{1}\right) d x_{1}$, where $f\left(x_{1}\right)=\frac{\overline{u_{1}(\vec{r}) u_{1}\left(\vec{r}+x_{1}\right)}}{\sigma_{u_{1}}^{2}}$

or

$L \doteq \bar{u} T=\bar{u} \int_{0}^{\infty} R_{E}(\tau) d \tau$

$\ddagger D / L^{\prime}$ where $L^{\prime}=x$ at $f(x)=0.37$

* Vertical Plane Array of anemometers

§ $\mathrm{D} / \mathrm{H}$ is used 


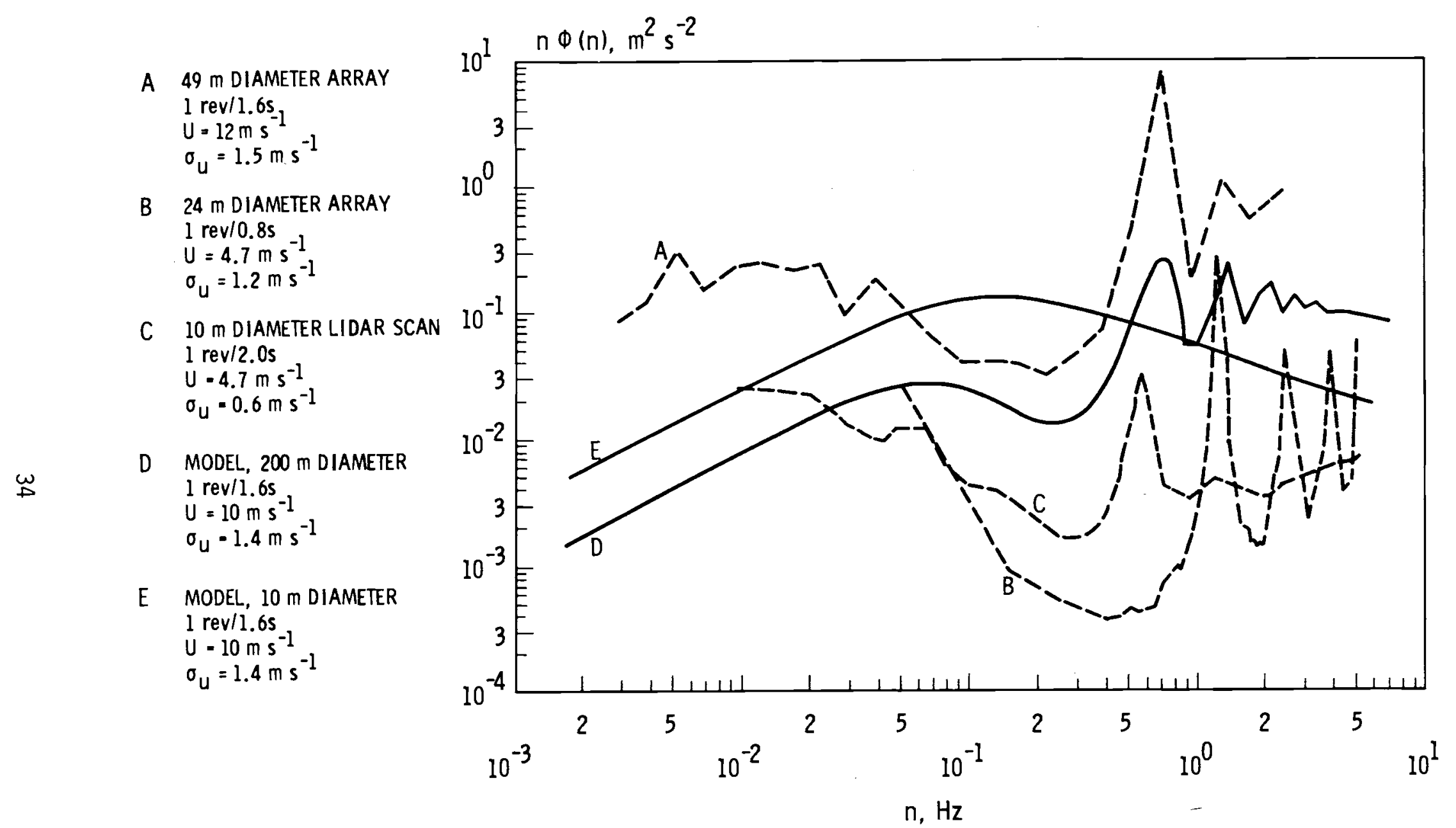

FIGURE 14. Comparison of the New Model of the Spectrum of Rotationally Sampled Turbulence Against Observed Spectra: a) 49 m Diameter Array, b) 24 m Diameter Array, c) 10 m Diameter Lidar Scans, d) Model (200 m Diameter Rotation) and e) Model (10 m Diameter Rotation) 
At the lowest-frequency spike, mean wind shear in the measured wind spectra accounts for much of the extra energy which is not found in the model, which excludes mean wind shear. 


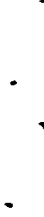

, 


\section{DISCUSSION}

The theoretical spectral model derived above provides a simple, more complete tool for assessing design criteria for horizontal axis wind turbines. Its accuracy remains to be tested. Until the model is modified to apply to horizontal-circle paths, we do not know that it applies as accurately to vertical axis wind turbines, though the effects are similar.

The theory requires modification for application to nonisotropic atmospheric conditions. It provides a framework about which a semiempirical model of spectra of rotationally sampled turbulence may be efficiently developed.

Transformations of gust probability distributions functions from the Eulerian reference frame to the rotating frame are required also. The general nature of the alterations expected in gust amplitude and in gust duration statistics are discussed in a previous report [8]. 
. 


\section{APPLICATION TO WIND TURBINE DESIGN}

The heuristic description of a rotor blade chopping across wind speed variations, or eddies, in a turbulence field, though incomplete, is useful. This situation is to be contrasted with that for a small anemometer fixed to a tower. It is totally immersed in the turbulence eddies, which it measures well. That is, the eddies are much larger than the anemometer. The anemometer rotor blades do not chop across them. Quite the opposite, it will measure wind velocity variations of, say, a $10 \mathrm{~m}$ diameter eddy, because the eddy is advected past the anemometer by the mean wind. If the mean speed of the wind is $10 \mathrm{~ms}^{-1}$, the anemometer wil1 observe a period of $1 \mathrm{~s}$ for the eddy. A much larger wind turbine rotor blade will move across the eddy about 10 times faster if the tip speed ratio, $\lambda_{T}$, has a value of 10 . The period of fluctuation observed by the blade will be about $0.1 \mathrm{~s}$. It is clear that eddies, which appear at the rotor blade to have even larger periods (lower frequencies than $10 \mathrm{~Hz}$ ), will engulf a large part of the span of the blade around the point of observation. This implies a strong correlation of wind velocity along the blade, even at $10 \mathrm{~Hz}$. It means that rotational analysis of turbulence around a single circular path in, e.g., the outer one-third of a blade will represent eddies which are large enough to cause most of the aerodynamic induced torque. This should be complete enough for many design purposes. Applying the model separately to several concentric circles would account for the effect on spectra of tip speed ratios and values of $\mathrm{o} / \mathrm{L}$ at different radial stations of the rotor blade. However, it would not account for instantaneous correlation between two greatly separated points on the blade. To this extent it might be slightly less accurate than optimal in estimating blade torque.

The design of a wind turbine requires placing turbine resonance frequencies as far away as practical from frequencies of large amounts of fluctuation energy in the wind and other sources of force. If the turbine response cannot be decoupled from wind fluctuations by choice of turbine resonance frequencies, then it must be designed to handle in some other way the fluctuations which will exist. This requires correct information about turbulence. 
Turbulence observed in a rotating frame of reference of a point on a turbine blade will cause unexpected high loads at frequencies greater than the blade rotation frequency. It may cause somewhat smaller loads and power at frequencies less than that of the blade rotation frequency. The specific character of the turbulence will vary with variation of both wind and turbine parameters. If turbulence is even potentially important in turbine design criteria, it is critically important to consider the turbulence characteristics that will be experienced by a rotating blade rather than by a stationary blade.

There are several reasons why the rotation rate of a turbine blade may be changed. It may be necessary to slow the turbine blade to a lower fixed rate and thus reduce the noise generated, as was done with the MOD-1 turbine at Boone, North Carolina. Since the resonance frequencies of the turbine were designed for a higher rotation rate, such a change of rotation rate may require taking into account the effect of rotational sampling on the observed spectrum of the wind. The asynchronous (variable speed) wind turbine has a distinctly different problem. It will experience a wide range of variations in the observed spectrum of turbulence. A positive factor is that the tip speed ratio may remain more constant at a given radius, which may partly compensate for variable rotation rate.

For fatigue analysis turbulence will be especially important in the frequency range $n=0.5 n_{0}$ to $10 n_{0} \mathrm{~Hz}$, where $n_{0}$ is the rotation frequency of the turbine blade.

Energy capture calculations should in principle take into account the rotational sampling effect. The depletion of fluctuation energy in the frequency range $n=0.03 n_{0}$ to $0.15 n_{0} \mathrm{~Hz}$ may be expected to affect energy capture calculations and turbine control programs if wind fluctuation periods of from 5 to $30 \mathrm{~s}$ are of interest. The effect is probably a 2 to $5 \%$ effect, which may be negligible.

An analysis of the nondimensionalized expression for the correlation function of axial wind speed in a rotating frame of reference leads to several conclusions. Small wind turbines will experience diminished rotational effects 
only if blade radius is very small or the local length scale of turbulence is quite large relative to the radius of the blade. It is especially important either to avoid wakes of rotor sized objects or to design the rotor to tolerate the turbulence whose spectral density function may be anticipated for this condition. Destruction of anemometer propellers has occurred in intensified smal1 scale turbulence with a $10 \mathrm{~ms}^{-1}$ mean wind speed, even though these propellers routinely survive turbulent winds up to $30 \mathrm{~ms}^{-1}$ on meteorological towers. The decrease in $L$ intensifies the rotational sampling effects. This may be an important factor in the destruction of these tiny wind turbines.

The analyses in this paper show that wind turbine survival in turbulence can be increased by raising turbines to greater heights, where the integral length scale, $L$, increases and sometimes the magnitude of the turbulence, $\sigma^{2}$, decreases. Other factors must be considered, however. Because the atmosphere is not generally isotropic or homogeneous, placing a wind turbine at greater heights may bring it into a region where additional wind effects occur. Wind velocity shears are not included in the theory developed above. Nevertheless, much guidance for design and operation of wind turbines can be derived from this simple theory. 


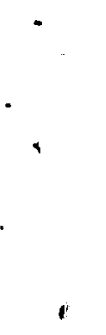




\section{CONCLUSIONS}

Wind turbulence characteristics at a rotating wind turbine blade are much different from those at a stationary blade simply because the wind is sampled rotationally around a circle instead of at a stationary point. The effect may be seen in graphs of wind speed as a function of time and in any of the characterizing statistics involving space and time scales of the wind. The function form of the gust probabilities or wind Fourier spectra also depend upon some space and time scales of the turbine rotor including the rotation rate, the radius of the blade, and the height of the rotor above the ground.

The wind turbine layer of the atmosphere is often heterogeneous and nonisotropic. Thus turbulence observed by a rotating turbine blade is best determined by measurements from circular arrays of anemometers or from circletraversing anemometers. However, the complexity of the measurements and analysis required makes it imperative to find methods of simplifying the problem. Recent theoretical work reported in this paper provides a generic method for obtaining the spectrum of the axial turbulence for homogeneous, isotropic conditions. The theory presented is quite suitable for qualitative analyses of energy density and quantitative analyses of cyclic frequencies at which effects occur.

Actual measurements of the wind are still preferred for quantitative analyses. The complete measurements cannot be made at all sites, but the combination of theory and measurements may be used to derive transformation functions. This will permit formulations of spectra and gust probabilities of nonisotropic turbulent wind for rotating wind turbine blades. Semiempirical models and simpler wind measurements from a single tower at a selected site will then suffice to characterize specific sites. The basis for this approach has been established by the work reported in this paper.

This work now makes it possible to develop turbine design, turbine siting and turbine operations and control programs in terms of atmospheric boundary layer properties observed by a rotating wind turbine blade. 


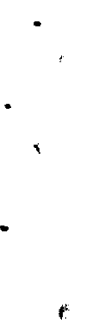




\section{REFERENCES}

1. M. G. Verholek, Preliminary results of a field experiment to characterize wind flow through a vertical plane. PNL-2518, Pacific Northwest Laboratory, Richland, Washington (1978).

2. W. E. Holley, R. W. Thresher and S-R Lin, Wind turbulence inputs for horizontal axis wind turbines. Proc. 2nd DOE/NASA Conference on Wind Turbine Dynamics, U.S. Department of Energy, 101-111 (1981).

3. H. H. Rosenbrock, Vibration and stability problems in large turbines having hinged blades. C/T 113, E.R.A., Surrey, England (1955).

4. T. von Karman, Progress in the statistical theory of turbulence. Proc. National Academy of Science, 34,530-539 (1948).

5. E. Janke and F. Emde, Tables of functions with formulae and curves. Dover (1945).

6. F.W.J. Olver, Bessel functions of integer order. Handbook of Mathematical Functions with Formulas, Graphs and Mathematical Tables, Applied Mathematics Series No. 55, U.S. National Bureau of Standards, 355-434 (1964).

7. N. W. McLachlan, Bessel functions for engineers. The Clarendon Press, Oxford, England (1955).

8. J. R. Conne11, Turbulence spectrum observed by a fast-rotating wind turbine blade. PNL-3426, Pacific Northwest Laboratory, Richland, Washington (1980). 


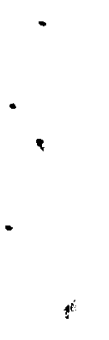




\section{ACKNOWLEDGMENTS}

The help of J. C. Doran in the acquisition and assurance of quality data from the $50 \mathrm{~m}$ diameter vertical plane array in May 1979, R. L. George's assistance in computing spectral density functions from the measured wind velocity time series, and the aid of D. C. Powell in computing spectral functions from the theoretical formulation, is greatfully acknowledged.

Special thanks go to F. F. Hall and R. M. Hardesty at the Wave Propagation Laboratory of the National Oceanic and Atmospheric Administration and to V. A. Sandborn at Colorado State University for making special measurements of turbulence using lidar and hotwire anemometers sweeping in circular paths.

Thanks also go to G. Fichtl, consultant and W. E. Holley at Oregon State University for providing the author with examples of spectra of turbulence computed using their theoretical models of turbulence experienced by a point on a rotating blade. Their models will be published in separate PNL reports.

A discussion with S. Frandsen and C. J. Christensen at RISO in Denmark in September 1979, which showed that the response spectra of the Danish Gedser Mi11 was consistent with the spectrum of turbulence observed at PNL in the revolving frame of reference, was especially stimulating. 
APPENDIX

A GUST CHARACTERIZATION OF THE TURBULENT WIND ENCOUNTERED BY A ROTATING TURBINE ROTOR 


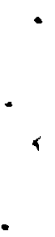




\section{A GUST CHARACTERIZATION OF THE TURBULENT WIND}

ENCOUNTERED BY A ROTATING TURBINE ROTOR

In the body of this report the description of wind measured in a rotating frame of reference is a spectral one. For some purposes a gust description of the wind may be more useful. The purpose of this appendix is to show the nature of the transformation of a gust description of wind which corresponds to changing the frame of observation from the conventional stationary one to a rotating one.

Turbulence characteristics experienced at nonmoving locations such as anemometers fixed to towers are used in conventional engineering design criteria. They may be modified easily to apply to systems moving in nearly straight lines into the wind. The modification consists of a simple compression of the time dimension so that wind fluctuations occur more rapidly but are otherwise the same as at nonmoving systems.

An example of this simple modification can be constructed for a car or airplane moving straight into the wind at a speed $V_{0}$. An anemometer on a tower in the same wind would experience wind speed changes because the air is moving past the anemometer while fluctuating about an average wind speed $\bar{V}_{\text {wind }}$ (see Figure A.1a). The moving car experiences a larger mean wind speed but the same amplitude of fluctuations. The fluctuations simply occur more rapidly (see Figure A.1b). In the simple wind model shown in Figure A.la there is only one sinusoidal frequency of fluctuation at the anemometer. Therefore there will be only one sinusoidal frequency of fluctuation occurring at the moving car. The period of fluctuation is reduced by a factor which is the ratio of the wind speed to the sum of the car speed plus the wind speed, $\bar{V}_{w} /\left(V_{0}+\bar{V}_{w}\right)$. The example in Figure $A .1$ is for a wind speed of $5 \mathrm{~ms}^{-1}$ and a car speed of $45 \mathrm{~ms}^{-1}$. If each cycle of wind fluctuation is considered to be a single gust of wind, the gust periods of $50 \mathrm{~s}$ are compressed to $5 \mathrm{~s}$ experienced by the moving car.

The wind environment experienced by a wind turbine is now compared to that of a car or airplane. The wind turbine situation is somewhat different because the blade of the turbine rotates in a circle of modest size compared 


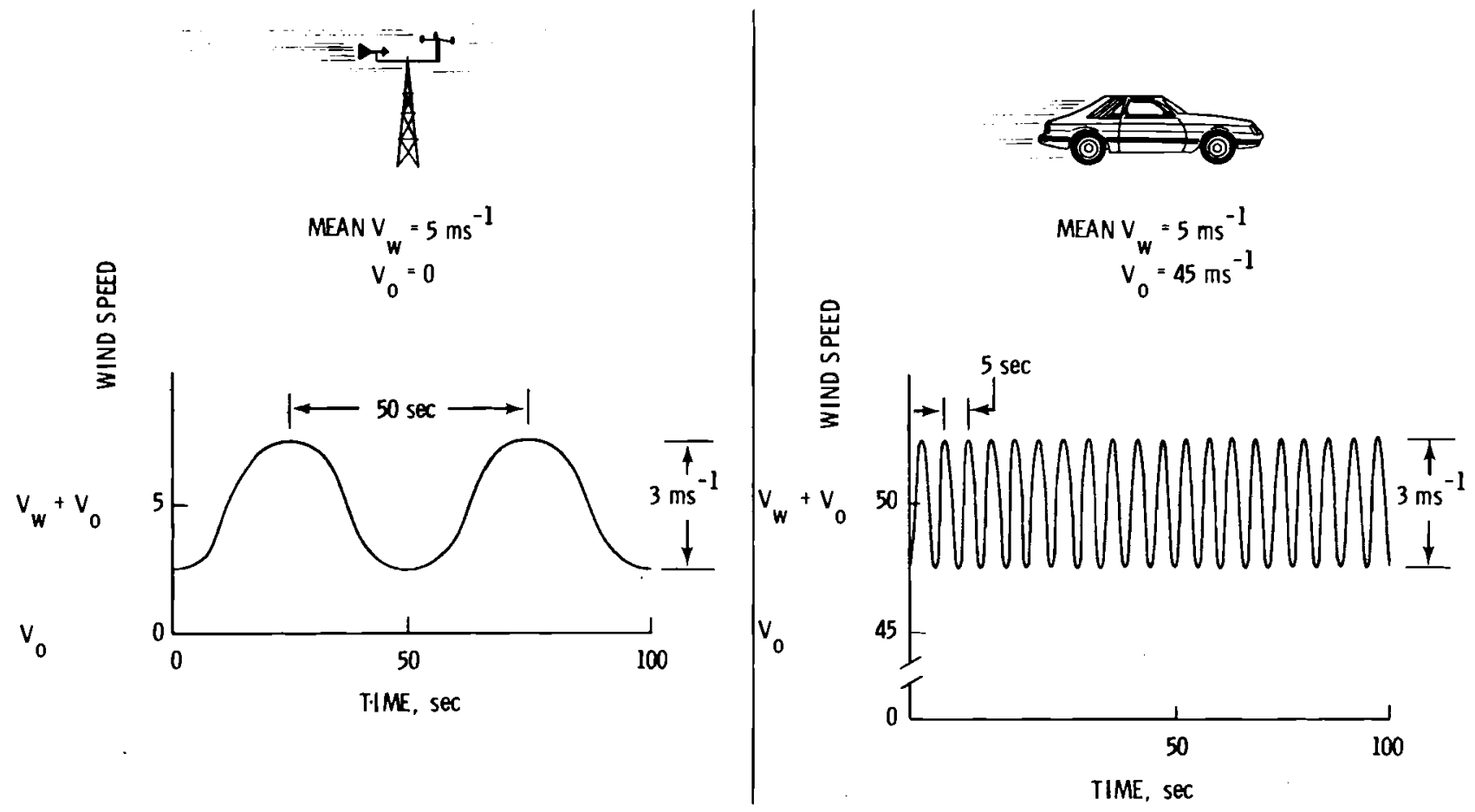

FIGURE P..1. Modification of the Observed Character of Fluctuating Wind Encountered at the Same Time by Two Differently Moving Systems: a) Stationary Tower Anemometer and b) Uniformly Moving Car on a Straight Path Into the Wind.

NOTE: The drawings and graphs are schematic. 
to the size of the largest turbulence eddies or gusts. A rotor blade never moves across these larger gusts by virtue of its own high speed in rotation. Instead, these large-eddy wind variations move past the rotor disk by the carrying action of the mean wind speed. (This is the same situation as for the anemometer propeller, which rotates in a very small circle. It accurately measures the variation of wind speed of the eddies blowing past it if they are 10 or so times larger than the propeller.) However, the large wind turbine blade does cross small eddies at high speed, with a resultant compression of the time scale of the fluctuation of wind speed for small eddies. Thus for small eddies, an effect is produced that is equivalent to the car or airplane moving straight into the wind.

An instructive comparison of the duration and amplitude of three different size of gusts observed in three differently moving frames of reference is given below. The gusts shown in Figure A.2a represent the conventional view of gusts of turbulence; they apply strictly only to direct wind forcing of nonmoving structures. The gusts would be seen from a moving car as in Figure A.2b. These gusts would be seen at a rotating wind turbine blade as shown in Figure A.2C. The rotor blade chops across the medium and small eddies but rotates well inside the large eddy. Some turbulence gusts measured by a tower anemometer may have the amplitudes and durations shown in Figure A.2a. The magnitudes of amplitude and duration are to be compared with those in Figures A.2b and A.2c. The shapes of the gusts are hypothetical. We take the gusts as represented in Figure A.2a to be large, medium and small gusts relative to the diameter of a wind turbine rotor. The actual size and wind speed spatial variation of the gusts is not changed by viewing them (whatever the motion of the frame of reference). In Figure A.2b the gusts appear to have shorter durations because the observation point is a car moving past the gusts. In Figure A.2C the large eddy is not seen to vary faster because the rotating blade does not cross even a significant part of the eddy. A significant part of the medium eddy is crossed at high speed and is thus seen to vary more rapidly. The blade crosses the eddy in a different direction than does the car. Therefore, its duration and amplitude at the blade do not necessarily correspond to those observed from the car, even though the linear speed of the 

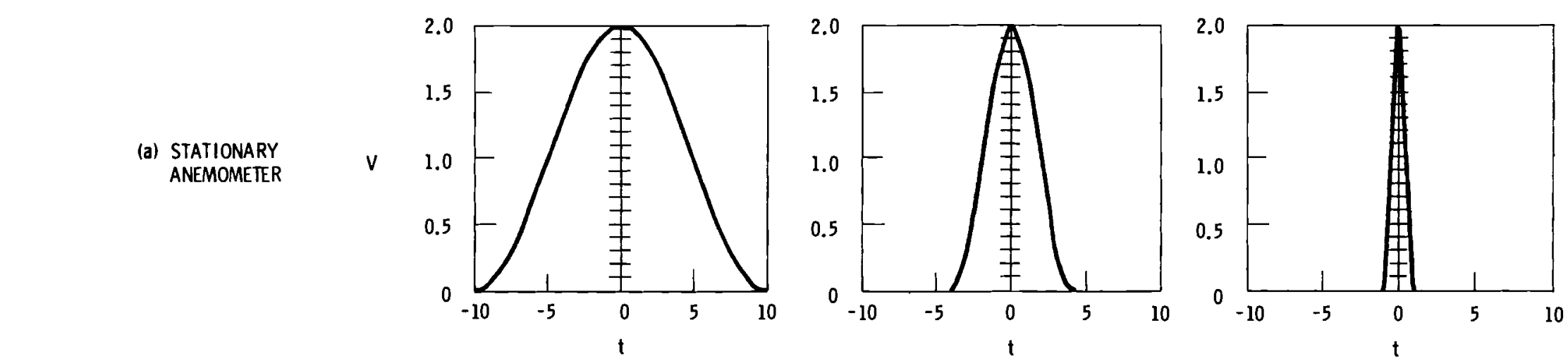

is
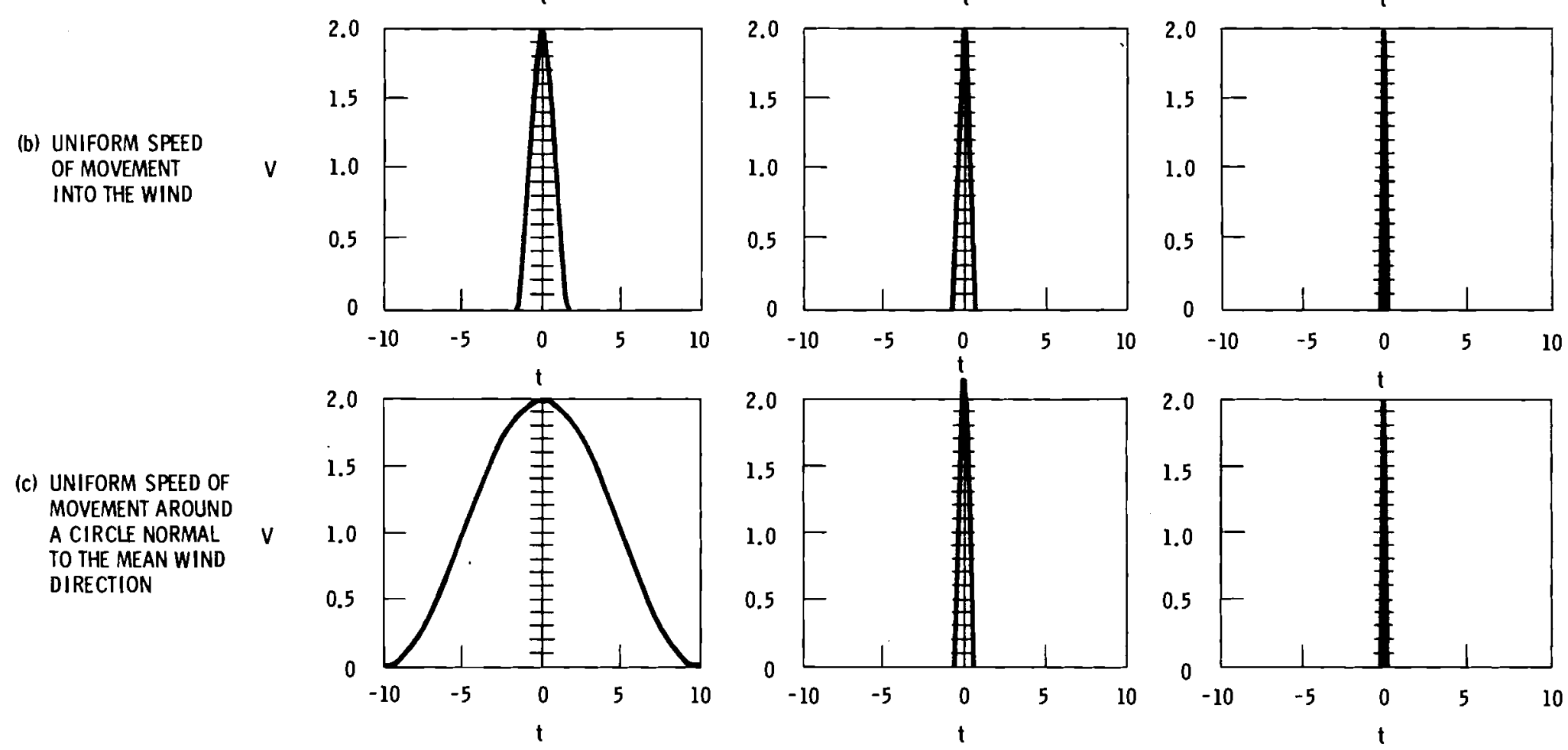

FIGURE A.2. Speed and Duration Curves of Three Sizes of Gust Observed From Three Different Frames of Reference. The abscissas are time in seconds. The ordinates are wind speed in $\mathrm{ms}^{-1}$. 
car and the point on the rotor blade are the same. The small eddy or gust is crossed effectively the same by the car and the rotor and identical changes in duration and amplitude are expected in each case.

The effect of rotation of the frame of reference from which fluctuations or gusts of wind speed are observed is to modify the probability or frequency of occurrence of gust amplitudes and durations which is applicable to turning rotors. Figure A.3, adapted from Doran and Powel1 [1], shows an example of the effect of rotating the observation point around a circle using data from the PNL vertical plane array at Hanford, Washington. (a) The dashed straight line in the figure is the probability density curve for the wind measured at a stationary point. The symbols trace curves for the same measured wind observed from a point rotating around a crosswind circle $49 \mathrm{~m}$ in diameter at a rate of one revolution per $1.6 \mathrm{~s}$. The difference in statistics for the nonrotating and the rotating case is quite significant if turbulence itself is significant in turbine design.

In general it may be expected that any characterization of wind fluctuations which involves time and space scales will be modified when the fluctuations are observed in the rotating frame of reference.

(a) The data are for the same array and time period described by connell1 [2]. The gust model used is the gust zero $\left(G_{0}\right)$ model that was developed by Powe11 and Connel1 [3] and used for real wind characterization by Doran and Powel1 [4]. 


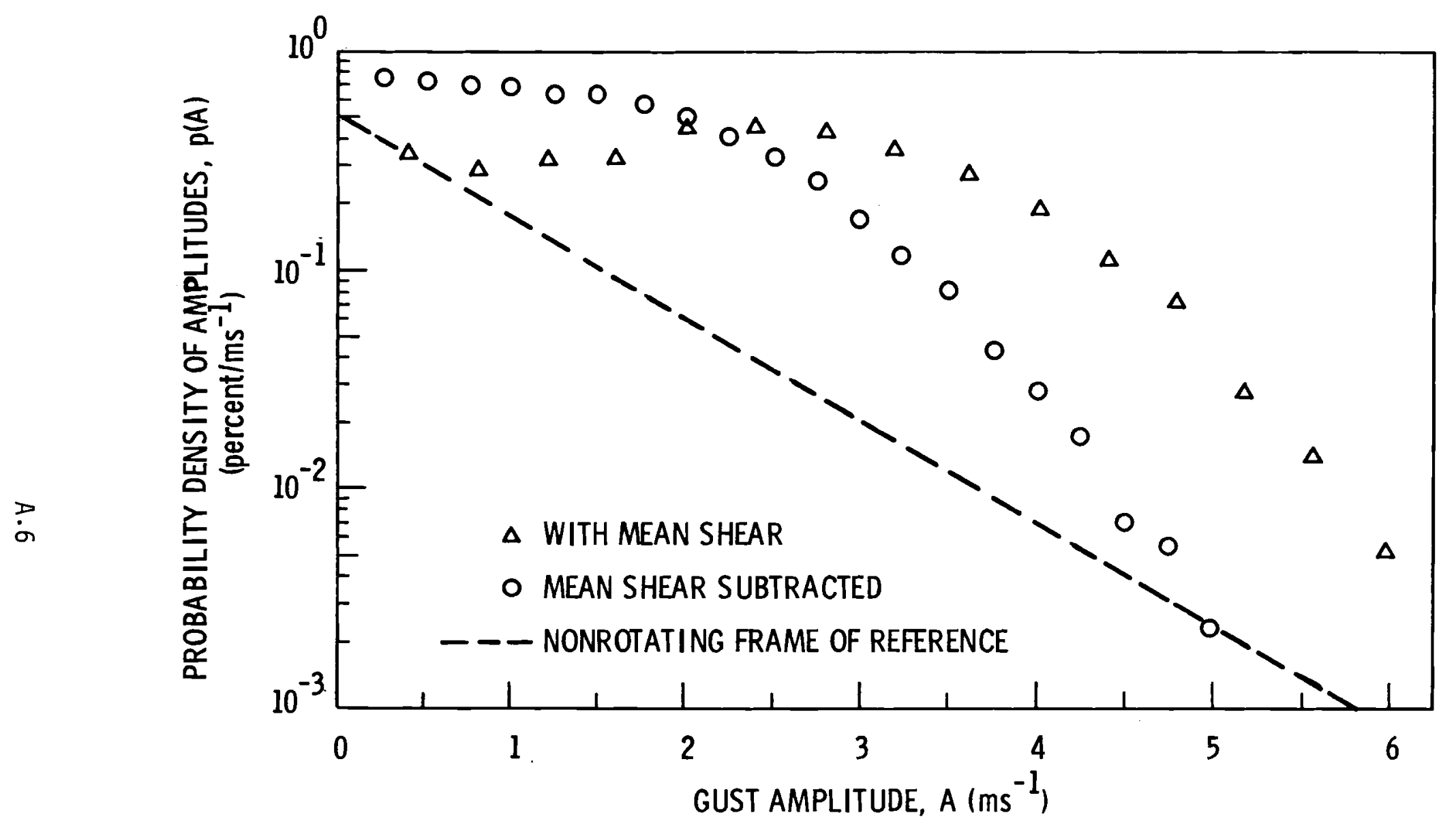

FIGURE A.3. Probability Density Distribution of Amplitudes Observed in the Rotating Frame of Reference for Gusts That are Characterized as Gust Zero Events [3]. The effect of observing from a rotating turbine blade is shown by the symbols $\Delta$ and 0 . The probability that a gust amplitude is greater than $A_{1}$ is

$$
P\left(A_{1}\right)=\int_{A_{1}}^{\infty} p(A) d A .
$$




\section{REFERENCES}

1. J. C. Doran and D. C. Powel1, Gust models for design and performance analysis of wind turbines. Proc. AIAA/SERI Wind Energy Conference, American Institute of Aeronautics and Astronautics, New York, 238-244 (1980).

2. J. R. Conne11, Turbulence spectrum observed by a fast-rotating wind turbine blade. PNL-3426, Pacific Northwest Laboratory, Richland, Washington (1980).

3. D. C. Powell and J. R. Connell, Definition of gust model concepts and review of gust models. PNL-3138, Pacific Northwest Laboratory, Richland, Washington (1980).

4. J. C. Doran and D. C. Powe11, Gust characteristics for WECS design and performance analysis. PNL-3421, Pacific Northwest Laboratory, Richland, Washington (1980). 


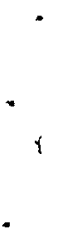




\section{DISTRIBUTION}

No. of

Copies

OFFSITE

A. A. Churm

DOE Chicago Patent Group

9800 S. Cass Avenue

Argonne, IL 60439

D. F. Ancona

Department of Energy

Wind Energy Technology Division

1000 Independence Avenue

Forrestal Building

Room 5F059

Washington, DC 20585

C. I. Aspliden

Department of Energy

Wind Energy Technology Division

1000 Independence Avenue

Forrestal Building

Room 5F067

Washington, DC 20585

L. V. Divone

Department of Energy

Wind Energy Technology Division

1000 Independence Avenue

Forrestal Building

Room 5F059

Washington, DC 20585

W. C. Reddick

Department of Energy

600 E Street N.W.

Washington, DC 20545

G. P. Tennyson

Department of Energy

Albuquerque Operations Office

P.0. Box 5400

Albuquerque, NM 87115

27 DOE Technical Information Center
No. of

Copies
D. K. Ai

Alcoa Laboratories

Alcoa Tech. Center

Alcoa Center, PA 15069

D. Nielson

Boeing Eng. and Const. Co.

P. 0. Box 3707, MS-9A-65

Seattle, WA 98124

N. Butler

Bonneville Power Administration

P.0. Box 3621

Portland, OR 97208

V. Sandborn

Engineering Research Center

Colorado State University

Fort Collins, CO 80523

T. Hoffer

Desert Research Institute

Atmospheric Sciences Center

University of Nevada System

P.0. Box 60220

Reno, NV 89506

J. E. Cummings

Electric Power Research Institute

$3412 \mathrm{Hillview} \mathrm{Avenue}$

Palo Alto, CA 94303

W. Frost

FWG Associates, Inc.

271A Lakewood Drive

Tullahoma, TN 37388

G. Ficht 1

7703 0akridge Drive

Huntsville, AL 35802 
No. of

Copies

S. Macklis

General Electric Company

Advanced Energy Systems

P.0. Box 8661

Philadelphia, PA 19101

J. M. Kos

Hamilton Standard

Bradley Field Road

Windsor Locks, CT 06096

J. Mayhew

Hamilton Standard, MS-IM3

Bradley Field Road

Windsor Locks, CT 06096

M. A. Bowes

Kaman Aerospace Corporation

01d Windsor Road

Bloomfield, CT 06095

T. R. Richard

NASA/LeRC

21000 Brookpark Road

Cleveland, $\mathrm{OH} \quad 44135$

D. Spera

NASA/LeRC

21000 Brookpark Road

Cleveland, $\mathrm{OH} 44135$

D. Lenschow

NCAR

P.0. Box 3000

Boulder, CO 80307

J. C. Wyngaard

NCAR

P.0. Box 3000

Boulder, CO 80307

J. Telford

Desert Research Institute

Atmospheric Sciences Center

University of Nevada System

P.0. Box 60220

Reno, NV 89506
No. of

Copies

F. $\mathrm{Hall}$

$\mathrm{RD} / \mathrm{R} 45 \times 2$

NOAA/ERL

Boulder, C0 80303

M. Hardesty

$\mathrm{RD} / \mathrm{R} 45 \times 2$

NOAA/ERL

Boulder, CO 80303

J. C. Kaimal

NOAA/ERL/WPL

3000 Marine Street

Boulder, CO 80302

W. Holley

Department of Mechanical Engr.

Oregon State University

Corvallis, OR 97331

R. Thresher

Department of Mechanical Engr.

Oregon State University

Corvallis, OR 97331

J. Dutton

Department of Meteorology

Pennsylvania State University

University Park, PA 16902

H. A. Panofsky

Department of Meteorology

Pennsylvania State University

University Park, PA 16802

A. C. Hansen

Rockwell International

P. 0. Box 464

Golden, C0 80401

E. G. Kadlec

Sandia Labs 4715

Box 5800

A1buquerque, NM 87165 
No. of

Copies

I. Vas

Solar Energy Research Institute

1617 Cole Boulevard

Golden, C0 80401

C. Weaver, Dean

University of Tennessee Space Institute

Tullahoma, TN 37388

T. Anderson

Westinghouse Electric Co.

P.0. Box 10824

Pittsburgh, PA 15236

R. H. Kirchhoff

Department of Mechanical Engr. University of Massachusetts

Amherst, MA 01003

A. B. Van Rennes

The Bendix Corporation

Executive offices

Bendix Center

Southfield, MI 48037

D. Fox

U.S. Forest Service Research Station

Fort Collins, C0 80522

F. S. Stoddard

U.S. Windpower Association

25 Adams Street

Burlington, MA 01803

R. Akins

Sandia Labs 4715

Box 5800

Albuquerque, NM 87165

H. Tieleman

Dept. of Engr. Sci. \& Mech.

Virginia Polytechnic and State University

Blacksburg, VA 24061
No. of

Copies

S. Chan

Systems Control, Inc.

1801 Page Mill Road

Palo Alto, CA 94304

E. A. DeMeo

Electric Power Research Institute

P.0. Box 10412

Palo Alto, CA 94303

W. A. Vashon

A. D. Little, Inc.

20 Acorn Park

Cambridge, MA 02140

ONSITE

1 DOE Richland Operations Office

P.0. Box 550

Richland, WA 99352

H. E. Ransom

87 Pacific Northwest Laboratory

Battelle Boulevard

Richland, WA 99352

W. R. Barchet

W. C. Cliff

J. R. Connell (50)

J. C. Doran

R. L. Drake

C. E. Elderkin

R. L. George

V. K. Hopkins (15)

A. H. Miller

E. L. Owczarski

W. T. Pennell

D. C. Powell

J. V. Ramsde 11

D. S. Renné

H. L. Wegley

L. L. Wendel 1

R. K. Woodruff

Technical Information Files (5)

Publishing Coordination (2) 


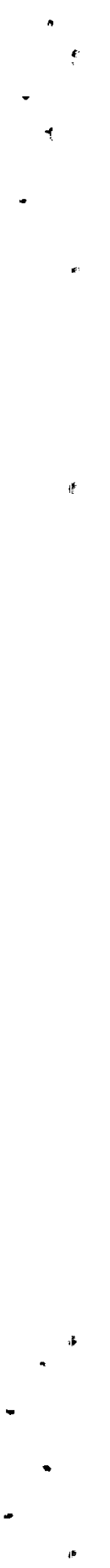

